\title{
Simulating secondary organic aerosol from anthropogenic and biogenic precursors: comparison to outdoor chamber experiments, effect of oligomerization on SOA formation and reactive uptake of aldehydes
}

\author{
Florian Couvidat $^{1}$, Marta G. Vivanco ${ }^{2}$, and Bertrand Bessagnet ${ }^{1, \mathrm{a}}$ \\ ${ }^{1}$ Institut National de l'Environnement Industriel et des Risques, Verneuil-en-Halatte, France \\ ${ }^{2}$ Centro de Investigaciones Energéticas, Medioambientales y Tecnológicas (CIEMAT), Departamento de Medio Ambiente, \\ Av. Complutense 40, 28040-Madrid, Spain \\ anow at: Hangzhou Futuris Environmental Technology Co. Ltd, Zhejiang Overseas High-Level Talent Innovation Park, \\ No. 998 WenYi Road, 311121, Hangzhou, Zhejiang, China
}

Correspondence: Florian Couvidat (florian.couvidat@ineris.fr)

Received: 14 December 2017 - Discussion started: 12 January 2018

Revised: 12 September 2018 - Accepted: 17 September 2018 - Published: 2 November 2018

\begin{abstract}
New parameterizations for the formation of organic aerosols were developed. These parameterizations cover secondary organic aerosol (SOA) formation from biogenic and anthropogenic precursors, $\mathrm{NO}_{x}$ dependency, oligomerization and the reactive uptake of pinonaldehyde. These parameterizations were implemented in a box model in which the condensation and/or evaporation of semi-volatile organic compounds was simulated by the Secondary Organic Aerosol Processor (SOAP) model to take the dynamic evolution of concentrations into account.

The parameterizations were tested against several experiments carried out in previous studies in the EUPHORE outdoor chamber. Two datasets of experiments were used: the anthropogenic experiments (in which SOA is formed mainly from a mixture of toluene, 1,3,5-trimethylbenzene and o-xylene) and the biogenic experiments (in which SOA is formed mainly from $\alpha$-pinene and limonene).

When assuming no wall deposition of organic vapors, satisfactory results (bias lower than $20 \%$ ) were obtained for the biogenic experiments and for most of the anthropogenic experiments. However, a decrease of SOA concentrations (up to $30 \%$ ) was found when taking wall deposition of organic vapors into account (with the parameters of Zhang et al., 2014). The anthropogenic experiments seem to indicate a complex $\mathrm{NO}_{x}$ dependency that could not be reproduced by the model. Oligomerization was found to have a strong effect on SOA
\end{abstract}

composition (oligomers were estimated to account for up to $78 \%$ of the SOA mass) and could therefore have a strong effect on the formation of SOA. The uptake of pinonaldehyde (which is a high-volatility semi-volatile organic compound, SVOC) onto acidic aerosol was found to be too slow to be significant under atmospheric conditions (no significant amount of SOA formed after 3 days of evolution), indicating that the parameterization of Pun and Seigneur (2007) used in some air quality models may lead to an overestimation of SOA concentrations. The uptake of aldehydes could nevertheless be an important SOA formation pathway for less volatile or more reactive aldehydes than pinonaldehyde.

Regarding viscosity, a low effect of viscosity on SOA concentrations was estimated by the model, although a decrease of SVOC evaporation was found when taking it into account, as well as a lower sensitivity of concentrations to changes of temperature during the experiments. 


\section{Introduction}

Because of the effect of fine particles on human health (WHO, 2003) and ecosystems (Kanakidou et al., 2005), the use of models has become a common practice to evaluate impacts and mitigation strategies. Particulate organic matter $(\mathrm{OM})$ represents a large fraction of the total fine particulate mass, typically between $20 \%$ and $60 \%$ (Kanakidou et al., 2005; Yu et al., 2007; Zhang et al., 2007), with the secondary fraction (secondary organic aerosol, SOA) representing most of it $(90 \%$ according to the best estimate of Kanakidou et al., 2005). Therefore, efforts have to be made to represent OM as accurately as possible in models.

Numerous models have been developed to simulate OM in 3-D air quality models (Schell et al., 2001; Donahue et al., 2006, 2011; Pun et al., 2002; Couvidat et al., 2012; Griffin et al., 2003; Jathar et al., 2015; Tulet et al., 2006; Carlton et al., 2010; Menut et al., 2013). Most of these models use simple parameterizations based on SOA yields estimated from smog chamber experiments conducted under specific conditions, which can be different from atmospheric conditions (low humidity, specific $\mathrm{NO}_{x}$ conditions). Nevertheless, SOA yields from chamber experiments have traditionally been estimated considering particle wall losses, but not gas wall losses. Several studies (Zhang et al., 2014, 2015; Bian et al., 2015; Cappa et al., 2016) indicate that this fact could have led to a strong underestimation of SOA yields. On the other side, none of these models take the whole complexity of the processes involved in organic aerosol formation (nonideality, multiphase partitioning, viscosity of the aerosol, phase separation, aging, oligomerization and organosulfate formation, effects of $\mathrm{NO}_{x}$ concentrations, etc.) into account, which can highly affect the level of SOA predicted (e.g., Ng et al., 2007a, b; Pun and Seigneur, 2007; Couvidat and Seigneur, 2011; Hall IV and Johnston, 2011). Therefore, the development of parameterizations addressing these aspects can provide insights about the SOA formation processes and improve current model estimates.

Oligomer formation has been addressed in some modeling studies. This process may be important for organic aerosol as it can transform semi-volatile and volatile organic compounds into less volatile compounds. Trump and Donahue (2014) studied the effect of oligomerization on the dynamic of organic aerosol formation. Pun and Seigneur (2007) developed a parameterization for the oligomerization of aldehydes by increasing their partitioning toward the particle. This parameterization (treating oligomerization with an equilibrium constant) has been used in Couvidat et al. (2012) to increase SOA formation from pinonaldehyde. High aerosol concentrations were simulated with this parameterization. However, Liggio and $\mathrm{Li}$ (2006b) showed that the uptake of pinonaldehyde onto acidic aerosol is a slow process and that this process could be due to oligomerization but also to organosulfate formation. Carlton et al. (2010) used a simple first-order rate constant of oligomerization for all organic compounds based on the results of Kalberer et al. (2004). Jathar et al. (2016) used the parameterization of Carlton et al. (2010) and showed that, depending on the mechanism, it could either have a strong effect on SOA formation or not. In all the cases, the authors found a strong effect on composition (or volatility distribution). Lemaire et al. (2016) compared these different approaches for oligomerization and emphasized the need to simulate oligomerization properly in air quality models.

Several approaches have been used to represent SOA formation in 3-D air quality models. Most of these approaches have in common that they are based on results from smog chamber experiments but differ in the methodology for lumping organic compounds and the treatment of the processes involved in SOA formation. Among these approaches, the volatility basis set (VBS) approach (Donahue et al., 2006; Robinson et al., 2007) has been widely used (Lane et al., 2008; Shrivastava et al., 2008; Murphy and Pandis, 2009; Shrivastava et al., 2011; Han et al., 2016). It uses a basis set in which semi-volatile organic compounds (SVOCs) are distributed on an equally spaced logarithmic scale for volatility (volatility bins). Aging was treated in the VBS by assuming a shift of volatility per aging step (gas-phase oxidation creates a change of volatility bins). A 1.5-D VBS (Koo et al., 2014) and a 2-D VBS (Donahue et al., 2011) were also developed to take changes in the oxidation degree into account.

Another approach used in 3-D air quality models is the molecular surrogate approach (Pun et al., 2002, 2006; Griffin et al., 2003; Couvidat et al., 2012). In this approach, surrogate compounds (that gather a large number of SVOCs with similar thermodynamic properties) are associated with molecular structures to extrapolate SOA formation from smog chambers to the atmosphere. In the molecular surrogate approach, several processes, which are often not taken into account in the other approaches, can be readily estimated (e.g., absorption into an aqueous phase, hygroscopicity, nonideality) and can be treated explicitly in the model. Based on this methodology, the Secondary Organic Aerosol Processor (SOAP) (Couvidat and Sartelet, 2015) was developed to simulate the gas-particle partitioning of SVOCs by taking nonideality (by considering the interactions between organic and inorganic compounds), multiphase partitioning, phase separation, hygroscopicity and the viscous state of organic aerosols into account. It was recently implemented in the CHIMERE air quality model (Couvidat et al., 2018) to simulate the gas-particle partitioning of SVOC formed with the $\mathrm{H}^{2} \mathrm{O}$ mechanism (Couvidat et al., 2012). However, in $\mathrm{H}^{2} \mathrm{O}$, a simplified aging mechanism was only applied for the first step of oxidation of anthropogenic primary SVOC due to lack of information, and SVOCs were supposed to be only hydrophilic (condense only the aqueous phase of particles) or only hydrophobic (condense only the organic phase of particles). Moreover, for anthropogenic SOA, comparison to measurements carried out inside EUPHORE has shown that for anthropogenic SOA the $\mathrm{H}^{2} \mathrm{O}$ mechanism may overestimate SOA in the conditions of the experiments. 
In order to create a SOA mechanism that could be implemented in 3-D air quality models and that considers the main phenomena involved in SOA formation (nonideality, multiphase partitioning, viscosity of the aerosol, phase separation, aging, oligomerization, effects of $\mathrm{NO}_{x}$ concentrations), the aim of this study is to improve and update the $\mathrm{H}^{2} \mathrm{O}$ mechanism for the formation of SOA from the oxidation of monoterpenes and aromatics by reconsidering some of the assumptions made in the development of this mechanism (no aging, compounds only hydrophilic or only hydrophobic, use of the parameterization of Pun and Seigneur, 2007) and have a more realistic representation of SOA formation. The update of the mechanism was done based on SOA yields available in the literature with the methodology of Odum et al. (1996); an aging mechanism was added and SVOC surrogates are assumed to be able to condense on both the aqueous phase and the organic phase. In order to evaluate this SOA mechanism, it was tested against some experiments carried out in the EUPHORE outdoor chamber under conditions different from the conditions under which it was developed (mixture of different compounds, noncontrolled temperature) to ensure the good performances of the model.

Two new parameterizations on particle-phase reactions were also developed covering oligomerization and the uptake of pinonaldehyde. For oligomerization, instead of representing this process with a first-order complete reaction as done by Carlton et al. (2010), it was chosen to reproduce this phenomenon (as an effort to provide a more realistic representation) with a second-order reversible reaction unfavored by humid conditions by analogy to oligomerization reactions expected to occur in the particle like esterification, hemiacetalization, aldolization and peroxyhemiacetalization (Roldin et al., 2014). For the uptake of pinonaldehyde, instead of assuming equilibrium (as done by Pun and Seigneur, 2007), a parameterization for the dynamic of the uptake, which was shown to limit strongly the uptake of pinonaldehyde (Liggio and $\mathrm{Li}, 2006 \mathrm{~b}$ ) as a function of the particle acidity, was taken into account.

In addition, the effect of particle-phase reactions was investigated. Oligomerization was simulated with the secondorder reversible reaction to evaluate the impact of this process and how it may impact SOA formation. For the uptake of pinonaldehyde onto acidic aerosols, the results obtained with the equilibrium-based parameterization of Pun and Seigneur (2007) were also compared to the results given by the dynamic parameterization developed in this study. SOA concentrations simulated with these parameterizations were compared to measured concentrations from experiments in the presence of $\mathrm{SO}_{2}$ (that leads to the formation of acidic aerosols). Finally, the effects of low diffusion inside the particle due to high viscosity and of wall losses of organic vapors were also studied.

\section{Method}

The new parameterizations described hereafter were developed and tested against experiments that were carried out in previous studies inside the outdoor chamber EUPHORE in Valencia, Spain.

\subsection{Experimental datasets}

EUPHORE is a $204 \mathrm{~m}^{3}$ hemispherical Teflon outdoor chamber located in Valencia (CEAM), Spain. The chamber is surrounded by retractable steel housing, which can be opened or closed to control the time of exposure to sunlight. The housing also serves to protect the chamber from rain and strong winds. The floor of the reactor consists of aluminum panels covered with Teflon, with a cooling system designed to compensate the heating of the chamber caused by solar irradiation. Two high-powered mixing fans (with an air flow of $4000 \mathrm{~m}^{3} \mathrm{~h}^{-1}$ ), located on the floor of the chamber, are used to ensure the homogeneous mixing of reactants and products. The EUPHORE facility is described in detail in Volkamer et al. (2001).

The experiments used for the comparison between the model and experiments have been published in previous studies (Vivanco et al., 2011, 2013). The experiments used in this study were initially planned to increase the experimental information regarding SOA formation and to be mainly used in model performance evaluation processes. As most of the studies at that time were focused on the oxidation of individual organic gases or simple mixtures of them, those experiments constitute a contribution to the experimental database on SOA formation, by considering the oxidation of different mixtures of organic precursors. Although the experimental dataset was designed for model evaluation purposes, it was not designed to evaluate the model developed in this study. Vivanco et al. (2016) and Santiago et al. (2012b) used these experiments to evaluate simple parameterizations existing in several air quality models. The experiments may not cover the full range of values covered by the model for some parameters, especially for relative humidity $(\mathrm{RH})$, which was lower than $40 \%$ for all experiments. Experimental conditions are described in Tables 1 and 2.

$\mathrm{OH}$ was formed by HONO photolysis. Ozone was formed throughout the experiment and often reached concentrations around $200 \mathrm{ppb}$. However, at the start of the experiments, in which concentrations of ozone are lower, monoterpenes will mainly react with $\mathrm{OH}$ radicals. As almost all the monoterpenes reacted during the first hour of the reaction, monoterpenes can be considered to react both with $\mathrm{OH}$ and $\mathrm{O}_{3}$. Calculations carried with RACM2 showed that $10 \%$ to $70 \%$ of the monoterpenes should have reacted with $\mathrm{O}_{3}$. For experiments B4 and B5 with very low relative humidities (around $10 \%$ ), most of the monoterpenes reacted with $\mathrm{OH}$ (around $90 \%$ ). $\mathrm{OH}$ photo-oxidation time (determined for a concen- 
Table 1. Initial concentrations in ppb, temperature $(T)$ in Kelvin and relative humidity in \% for biogenic experiments.

\begin{tabular}{lrccrrrrrr}
\hline Experiment & Isoprene & $\alpha$-Pinene & Limonene & $\mathrm{NO}$ & $\mathrm{NO}_{2}$ & $\mathrm{HONO}$ & $\mathrm{SO}_{2}$ & $T$ & $\mathrm{RH}$ \\
\hline B1 & 107 & 66 & 58 & 34 & 128 & 99 & 0 & $302-307$ & $0.5-3$ \\
$\mathrm{~B} 2$ & 92 & 50 & 50 & 48 & 0 & 87 & 0 & $298-300$ & $30-26$ \\
$\mathrm{~B} 3$ & 122 & 71 & 40 & 41 & 0 & 53 & 0 & $297-300$ & $19-22$ \\
$\mathrm{~B} 4$ & 0 & 63 & 65 & 32 & 0 & 101 & 0 & $294-298$ & $8-13$ \\
$\mathrm{~B} 5$ & 99 & 59 & 53 & 150 & 0 & 307 & 0 & $295-297$ & $8-11$ \\
$\mathrm{~B} 6$ & 87 & 50 & 51 & 244 & 89 & 40 & 513 & $295-300$ & $15-19$ \\
$\mathrm{~B} 7$ & 55 & 79 & 76 & 198 & 0 & 165 & 461 & $302-305$ & $20-30$ \\
\hline
\end{tabular}

Table 2. Initial concentrations in ppb, temperature $(T)$ in Kelvin and relative humidity in $\%$ for anthropogenic experiments. $\mathrm{SO}_{2}$ was not present for those experiments.

\begin{tabular}{lrcrrrrrrr}
\hline Experiment & Toluene & o-Xylene & TMB & Octane & NO & $\mathrm{NO}_{2}$ & HONO & $T$ & $\mathrm{RH}$ \\
\hline A1 & 102 & 22 & 153 & 85 & 19 & 0 & 99 & $299-305$ & $10-16$ \\
$\mathrm{~A} 2$ & 200 & 49 & 300 & 155 & 23 & 0 & 75 & $302-305$ & $9-18$ \\
$\mathrm{~A} 3$ & 48 & 11 & 106 & 42 & 23 & 0 & 71 & $302-307$ & $6-14$ \\
$\mathrm{~A} 4$ & 98 & 24 & 160 & 79 & 37 & 0 & 156 & $297-307$ & $6-13$ \\
$\mathrm{~A} 5$ & 97 & 21 & 146 & 81 & 4 & 8 & 52 & $297-308$ & $7-14$ \\
$\mathrm{~A} 6$ & 93 & 22 & 146 & 78 & 21 & 0 & 94 & $300-308$ & 0.4 \\
$\mathrm{~A} 7$ & 107 & 26 & 160 & 89 & 21 & 0 & 89 & $306-309$ & $7-10$ \\
$\mathrm{~A} 8$ & 116 & 29 & 19 & 10 & 57 & 0 & 119 & $302-305$ & $15-18$ \\
$\mathrm{~A} 9$ & 81 & 21 & 118 & 65 & 31 & 0 & 90 & $299-303$ & $28-37$ \\
\hline
\end{tabular}

tration of $1.5 \times 10^{6}$ molecules $\mathrm{cm}^{-3}$ ) was determined to range from a few hours to more than a day.

Two datasets of experiments are used: (i) the anthropogenic experiments where SOA is formed from the oxidation of toluene (TOL), 1,3,5-trimethylbenzene (TMB) and to a lesser extent 0 -xylene and octane and (ii) the biogenic experiments where SOA is formed from $\alpha$-pinene (API) and limonene (LIM) and to a lesser extent isoprene. Experimental conditions for the anthropogenic and biogenic experiments are described, respectively, in Tables 1 and 2. For the biogenic dataset, two experiments were carried out in the presence of $\mathrm{SO}_{2}$ to evaluate the parameterization of Pun and Seigneur (2007). Due to its low SOA yield, SOA from isoprene oxidation should not represent a significant amount of total SOA.

Although octane is a precursor of SOA and is present in the anthropogenic experiments, SOA formation from octane oxidation was not taken into account in this study as Vivanco et al. (2016) showed with an experiment in the same chamber that octane leads to an insignificant amount of SOA. Due to its low yield (0.5\% according to Lim and Ziemann, 2005), octane SOA should not represent more than a few percent of total SOA.

PM volume concentrations were measured with a Scanning Mobility Particle Sizer Spectrometer (SMPS). Data are not corrected for wall losses as the deposition of particles is taken into account in the model.

\subsection{Model development}

Secondary organic aerosols inside the chamber were simulated by coupling the gas-phase mechanism RACM2 (Goliff et al., 2013) with the SOAP model (Couvidat and Sartelet, 2015) to compute the dynamic formation of SOA. RACM2 was used because it has been shown to perform well for oxidant formation (Kim et al., 2009). To represent the chemical evolution of SVOC, RACM2 was modified to take the formation of the surrogate species into account according to the mechanisms described hereafter. The ROS2 algorithm (Verwer et al., 1999) was used to solve the chemical kinetic equations.

SOAP is a model designed to be modular with user options depending on the computation time. SOAP uses the molecular surrogate approach to estimate several properties and parameters (hygroscopicity, absorption into the aqueous phase of particles, activity coefficients and phase separation) and to evaluate the partitioning of organic compounds between one or several organic phases (the number of organic phases is determined by the Gibbs energy minimization) and the inorganic phase. It accounts for the influence of interactions between organic and inorganic compounds by using the AIOMFAC algorithm (Zuend et al., 2008, 2011; Zuend and Seinfeld, 2012). Secondary inorganic aerosol formation was added to the SOAP model by using the equilibrium parameters of ISORROPIA v2.1 (Fountoukis and Nenes, 2007). 
Currently, SOAP assumes that inorganic aerosols are metastable liquids and therefore does not take efflorescence or deliquescence processes into account. This assumption could be wrong in the presence of ammonia due to the low humidity inside the chamber, as ammonium sulfate would probably be solid as the humidity in the chamber (below $40 \%$ ) is always far below the deliquescence relative humidity $(80 \%$ at $298 \mathrm{~K})$. However, no ammonia was present in these experiments and $\mathrm{SO}_{2}$ was only introduced for two experiments. For those two experiments, $\mathrm{SO}_{2}$ oxidation will lead to sulfuric acid formation which remains liquid over the full RH range (Seinfeld and Pandis, 1998).

Several experimental data were used to constrain the model. Temperature and relative humidity measurements inside the chamber were used as inputs for the model. SMPS measurements were used to compute the mean diameter of particles. As modeling properly nucleation and coagulation of particles would be needed to simulate the size distribution of particles adequately, particles were gathered inside a single diameter bin. The mean diameter of particles was constrained to provide the model with a realistic estimation of the diameter without modeling the nucleation in SOAP. The diameter of the particle is used to compute the kinetic rate of condensation and/or evaporation and/or diffusion and the Kelvin effect by the dynamic approach of SOAP.

The model results were compared to non-corrected (according to wall losses) results. Wall deposition of particles was simulated via the first-order loss rate parameter constrained to reproduce the loss of particles during the last hours of the experiment when the chamber was enclosed by the retractable steel housing.

Wall losses of vapors were not taken into account due to the lack of information on deposition onto EUPHORE walls. However, in the last section, the effect of vapor wall losses on SOA formation in the chamber was investigated by taking vapor wall losses into account according to parameters estimated by Zhang et al. (2014).

\subsubsection{SOA mechanism}

A new mechanism was developed for SOA formation from toluene (TOL), o-xylene (XYL) and trimethylbenzene (TMB). Parameters were fitted on data issued from several studies under low and high $\mathrm{NO}_{x}$ conditions: $\mathrm{Ng}$ et al. (2007b) for toluene SOA, Cocker III et al. (2001) for TMB SOA and the results from both studies for xylene SOA. No information was found on SOA formation from TMB oxidation under low $\mathrm{NO}_{x}$ conditions; therefore, the stoichiometric coefficient from the low $\mathrm{NO}_{x}$ conditions for xylene was used. Similarly to Vivanco et al. (2016), the low $\mathrm{NO}_{x}$ condition yields are only used if radicals formed from the oxidation of the precursors react at least twice with the $\mathrm{HO}_{2}$ radical, to prevent high formation of low $\mathrm{NO}_{x} \mathrm{SOA}$ under intermediate $\mathrm{NO}_{x}$ conditions. Molecular structures (used by SOAP to estimate several properties and to compute activity coefficients) were selected based on the results of Im et al. (2014) by selecting the compound with a similar volatility, formed in the largest quantity and ensuring the best reproduction of the $\mathrm{O} / \mathrm{C}$ and $\mathrm{H} / \mathrm{C}$ ratios. Properties of surrogate species and reactions are shown in Table 3. Reactions leading to SOA formation are shown in Table 4 for TOL SOA and in Table 5 for XYL and TMB SOA.

For monoterpenes, the mechanism of Pun et al. (2006) was updated using results from more recent studies. For SOA formation from $\alpha$-pinene, $\beta$-pinene and limonene ozonolysis, the mechanism is based on the parameterizations described in Lee et al. (2011) for high and low $\mathrm{NO}_{x}$ conditions. The API $+\mathrm{OH}$ reaction is based on the results of Svendby et al. (2008), whereas for the LIM + OH reaction, the yield of $\mathrm{BiA} 2 \mathrm{D}$ was optimized to give the best results. Reactions and properties of surrogate species are shown in Tables 6 and 3 . The terpene $+\mathrm{NO}_{3}$ yields are based on Fry et al. (2014).

In the surrogate SOA approach, results of the model may depend on the choice of the surrogate structure to represent SOA formation. Although different VOCs form different compounds (or the same compounds in different quantities), this approach lumps together species that have similar properties (like saturation vapor pressure) and that are expected to have similar chemical structure. For example, firstgeneration aldehyde products from terpene oxidation were represented by the surrogate species BiA0D. Moreover, the compounds were selected (based on the best information available on SOA products) to reproduce the mean properties of SOA and of the O / C and $\mathrm{H} / \mathrm{C}$ ratios. Kim et al. (2014) showed that the mean $\mathrm{O} / \mathrm{C}$ and $\mathrm{H} / \mathrm{C}$ ratios are around $0.34-$ 0.36 and $1.4-1.5$ for SOA from $\alpha$-pinene and limonene, respectively. The selected surrogates give a $\mathrm{O} / \mathrm{C}$ ratio between 0.3 and 0.44 and $\mathrm{H} / \mathrm{C}$ ratio between 1.55 and 1.6. For TOL $\mathrm{SOA}$, the chosen surrogates give a $\mathrm{O} / \mathrm{C}$ ratio (between 0.71 and 0.8 ) and $\mathrm{H} / \mathrm{C}$ ratio (between 1.14 and 1.6) similar to the reported values by Schilling (2015) (between 0.7 and 0.8 for $\mathrm{O} / \mathrm{C}$ and between 1.2 and 1.6 for $\mathrm{H} / \mathrm{C}$ ). For TMB SOA, Sato et al. (2012) indicate a $\mathrm{O} / \mathrm{C}$ ratio around 0.4-0.6 and a $\mathrm{H} / \mathrm{C}$ ratio around 1.5-1.7. The chosen surrogates reproduce the $\mathrm{O} / \mathrm{C}$ ratio (between 0.38 and 0.55 ) but seem to underestimate the high $\mathrm{H} / \mathrm{C}$ ratio (between 1.13 and 1.44 due to the low $\mathrm{H} / \mathrm{C}$ ratio of the AnIP2 compound). However, for AnIP2, a better molecular structure with a similar O / C ratio and saturation vapor pressure could not be found.

The mechanism of Couvidat and Seigneur (2011) was used to simulate SOA formation from isoprene. 
Table 3. Properties of the different surrogate SOA species.

\begin{tabular}{|c|c|c|c|c|}
\hline Surrogate & Molecular structure & $\mathrm{MW}^{\mathrm{a}}$ & $P^{0 \mathrm{~b}}$ & $\Delta \mathrm{H}_{\mathrm{vap}}{ }^{\mathrm{c}}$ \\
\hline AnRP1 & & 202 & $1.01 \times 10^{-7}$ & 50 \\
\hline AnRP2 & & 160 & $2.68 \times 10^{-7}$ & 50 \\
\hline AnIP1 & & 132 & $2.36 \times 10^{-6}$ & 50 \\
\hline AnIP2 & & 167 & $1.24 \times 10^{-5}$ & 50 \\
\hline AnPER & & 190 & non-volatile & - \\
\hline AnRP1a & AnRP1 +1 group $\mathrm{OH}$ & 218 & non-volatile & - \\
\hline AnRP2a & $\mathrm{AnRP} 2+1$ group $\mathrm{OH}$ & 176 & non-volatile & - \\
\hline AnIP1a & AnIP1 +1 group $\mathrm{OH}$ & 148 & $1.36 \times 10^{-7}$ & 50 \\
\hline AnIP2a & AnIP2 +1 group $\mathrm{OH}$ & 183 & $2.58 \times 10^{-7}$ & 50 \\
\hline AnIP2b & AnIP2a +1 group $\mathrm{OH}$ & 199 & $5.39 \times 10^{-9}$ & 50 \\
\hline BiA0D & pinona & 168 & $1.0 \times 10^{-3}$ & 50 \\
\hline BiA1D & pinonic acid & 184 & $5.61 \times 10^{-5}$ & 50 \\
\hline $\mathrm{BiA} 2 \mathrm{D}$ & pinic acid & 186 & $1.67 \times 10^{-6}$ & 50 \\
\hline $\mathrm{BiA} 3 \mathrm{D}$ & 3-methyl-1,2,3-butanetricarboxylic acid & 202 & non-volatile & - \\
\hline
\end{tabular}

${ }^{\mathrm{a}}$ Molecular weight $\left(\mathrm{g} \mathrm{mol}^{-1}\right) .{ }^{\mathrm{b}}$ Saturation vapor pressure (torr) at $298 \mathrm{~K} .{ }^{\mathrm{c}}$ Enthalpy of vaporization $\left(\mathrm{kJ} \mathrm{mol}^{-1}\right)$.

\subsubsection{Oligomerization}

Carlton et al. (2010) developed a parameterization for oligomerization based on a simple first-order rate constant of oligomerization. Based on the results of Kalberer et al. (2004) indicating $50 \%$ of polymers after $20 \mathrm{~h}$ in TMB SOA, Carlton et al. (2010) determined a kinetic constant of $9.6 \times$ $10^{-6} \mathrm{~s}^{-1}$. However, this number was obtained with laser desorption ionization-mass spectrometry (LDI-MS) by taking all compounds with $m / z$ higher than 400 (with $m$ the ion mass and $z$ the ion charge) into account and not always taking small oligomers (dimers or trimers that may be formed more rapidly) into account. Kalberer et al. (2004) and Kalberer et al. (2006) also studied the oligomer fraction based on a volatility tandem differential mobility analyzer (VTDMA) giving the remaining volume fraction of particles at different temperatures. They found that for TMB SOA, the remaining fraction at $100^{\circ} \mathrm{C}$ after $5 \mathrm{~h}$ ranges from $50 \%$ to $62 \%$ and is composed of small oligomers or very low-volatility 
Table 4. Reactions leading to SOA formation* from toluene (referred to as TOL).

\begin{tabular}{ll}
\hline Reaction & $\left.\begin{array}{l}\text { Kinetic rate parameter } \\
(\text { molecule }\end{array} \mathrm{cm}^{3} \mathrm{~s}^{-1}\right)$
\end{tabular}

* Oxidants may be present as both reactants and products, so a reaction added to RACM2 will not affect the original photochemical oxidant concentrations. $\mathrm{MO}_{2}$ and $\mathrm{ACO}_{3}$ are the methyl peroxy radical and the peroxyacetyl radical, respectively. $\mathrm{A}$ is either $\mathrm{NO}, \mathrm{NO}_{3}, \mathrm{MO}_{2}$ or $\mathrm{ACO}_{3}$.

Table 5. Reactions leading to SOA formation* from o-xylene (referred to as XYL) and 1,3,5-trimethylbenzene (referred to as TMB).

\begin{tabular}{|c|c|}
\hline Reaction & 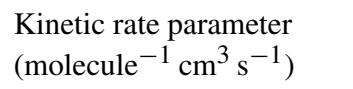 \\
\hline $\mathrm{XYL}+\mathrm{OH} \rightarrow \ldots+0.274 \mathrm{XYLP}$ & $1.70 \times 10^{-11} \times \exp \left(\frac{116}{T}\right)$ \\
\hline $\mathrm{XYLP}+\mathrm{HO}_{2} \rightarrow \mathrm{XYLlowNOx}+\mathrm{HO}_{2}$ & See $\mathrm{TOLP}+\mathrm{HO}_{2}$ reaction \\
\hline $\mathrm{XYLP}+\mathrm{A} \rightarrow \mathrm{XYLhighNOx}+\mathrm{A}$ & See TOLP + A reaction \\
\hline $\mathrm{XYLlowNOx}+\mathrm{OH} \rightarrow \mathrm{XYLlowNOxRAD}+\mathrm{OH}$ & $6.90 \times 10^{-11}$ \\
\hline $\mathrm{XYLhighNOx}+\mathrm{OH} \rightarrow \mathrm{XYLlowNOxRAD}+\mathrm{OH}$ & $6.90 \times 10^{-11}$ \\
\hline XYLlowNOxRAD $+\mathrm{HO}_{2} \rightarrow 0.611 \mathrm{AnPER}+\mathrm{HO}_{2}$ & See $\mathrm{TOLP}+\mathrm{HO}_{2}$ reaction \\
\hline $\mathrm{XYLlowNOxRAD}+\mathrm{A} \rightarrow 0.0529 \mathrm{AnRP} 1+0.344 \mathrm{AnIP} 2+\mathrm{A}$ & See TOLP + A reaction \\
\hline XYLhighNOxRAD $+\mathrm{HO}_{2} \rightarrow 0.0529 \mathrm{AnRP} 1+0.344 \mathrm{AnIP} 2+\mathrm{HO}_{2}$ & See $\mathrm{TOLP}+\mathrm{HO}_{2}$ reaction \\
\hline XYLhighNOxRAD $+\mathrm{A} \rightarrow 0.0529$ AnRP1 + 0.344 AnIP2 + A & See TOLP + A reaction \\
\hline $\mathrm{TMB}+\mathrm{OH} \rightarrow \ldots+0.274 \mathrm{TMBP}$ & $5.67 \times 10^{-11}$ \\
\hline $\mathrm{TMBP}+\mathrm{HO}_{2} \rightarrow$ TMBlowNOx $+\mathrm{HO}_{2}$ & See $\mathrm{TOLP}+\mathrm{HO}_{2}$ reaction \\
\hline $\mathrm{TMBP}+\mathrm{A} \rightarrow \mathrm{TMBhighNOx}+\mathrm{A}$ & See TOLP + A reaction \\
\hline TMBlowNOx $+\mathrm{OH} \rightarrow$ TMBlowNOxRAD $+\mathrm{OH}$ & $6.90 \times 10^{-11}$ \\
\hline TMBhighNOx $+\mathrm{OH} \rightarrow$ TMBlowNOxRAD $+\mathrm{OH}$ & $6.90 \times 10^{-11}$ \\
\hline TMBlowNOxRAD $+\mathrm{HO}_{2} \rightarrow 0.611 \mathrm{AnPER}+\mathrm{HO}_{2}$ & See $\mathrm{TOLP}+\mathrm{HO}_{2}$ reaction \\
\hline TMBlowNOxRAD $+\mathrm{A} \rightarrow 0.0117$ AnRP1 $+0.250 \mathrm{AnIP} 2+\mathrm{A}$ & See TOLP + A reaction \\
\hline TMBhighNOxRAD $+\mathrm{HO}_{2} \rightarrow 0.0117 \mathrm{AnRP} 1+0.250 \mathrm{AnIP} 2+\mathrm{HO}_{2}$ & See $\mathrm{TOLP}+\mathrm{HO}_{2}$ reaction \\
\hline TMBhighNOxRAD $+\mathrm{A} \rightarrow 0.0117$ AnRP1 +0.250 AnIP2 $+\mathrm{A}$ & See TOLP + A reaction \\
\hline
\end{tabular}

* Oxidants may be present as both reactants and products, so a reaction added to RACM2 will not affect the original photochemical oxidant concentrations. $\mathrm{MO}_{2}$ and $\mathrm{ACO}_{3}$ are the methyl peroxy radical and the peroxyacetyl radical, respectively. $\mathrm{A}$ is either NO, $\mathrm{NO}_{3}, \mathrm{MO}_{2}$ or $\mathrm{ACO}_{3}$

organic compounds. The remaining fraction at $100^{\circ} \mathrm{C}$ can even reach $80 \%$ to $90 \%$ after $25 \mathrm{~h}$. Based on these results, and assuming that the remaining fraction is mainly composed of small oligomers and that oligomerization is irreversible, the first-order constant of oligomerization should be around $3.85 \times 10^{-5} \mathrm{~s}^{-1}$ to take small oligomer formation into account.

However, a first-order complete reaction may not be appropriate to represent oligomerization. Indeed, Roldin et al.
(2014) showed that oligomerization should involve secondorder reversible reactions like esterification, hemiacetalization, aldolization and peroxyhemiacetalization. The equilibrium of these reactions is unfavored by humid conditions and the reaction is catalyzed under acidic conditions. Indeed, oligomer formation by esterification was reported in the case of isoprene SOA (Surratt et al., 2006).

In this study, oligomerization is represented by a reversible process which is mainly due to mechanisms like esterifica- 
Table 6. Reactions leading to SOA formation* from $\alpha$-pinene (referred to as API), $\beta$-pinene (referred to as BPI) and limonene (referred to as LIM).

\begin{tabular}{|c|c|}
\hline Reaction & $\begin{array}{l}\text { Kinetic rate parameter } \\
\left(\text { molecule }-1 \mathrm{~cm}^{3} \mathrm{~s}^{-1}\right)\end{array}$ \\
\hline $\begin{array}{l}\mathrm{API}+\mathrm{OH} \rightarrow 0.30 \mathrm{BiA} 0 \mathrm{D}+0.40 \mathrm{BiA} 2 \mathrm{D}+\mathrm{OH} \\
\mathrm{API}+\mathrm{O}_{3} \rightarrow \mathrm{APIO} 3 \mathrm{RAD}+\mathrm{O}_{3} \\
\mathrm{APIO} 3 \mathrm{RAD}+\mathrm{HO}_{2} \rightarrow 0.024 \mathrm{BiA} 3 \mathrm{D}+0.15 \mathrm{BiA} 2 \mathrm{D}+0.38 \mathrm{BiA} 1 \mathrm{D}+\mathrm{HO}_{2} \\
\mathrm{APIO} \mathrm{RAD}+\mathrm{NO} \rightarrow 0.085 \mathrm{BiA} 2 \mathrm{D}+0.24 \mathrm{BiA} 1 \mathrm{D}+\mathrm{NO} \\
\mathrm{API}+\mathrm{NO}_{3} \rightarrow 0.70 \mathrm{BiA} 0 \mathrm{D}+\mathrm{NO}_{3}\end{array}$ & $\begin{array}{l}1.21 \times 10^{-11} \times \exp \left(\frac{440}{T}\right) \\
5.00 \times 10^{-16} \times \exp \left(\frac{-530}{T}\right) \\
4.10 \times 10^{-13} \times \exp \left(\frac{790}{T}\right) \\
8.8 \times 10^{-13} \times \exp \left(\frac{180.2}{T}\right) \\
1.19 \times 10^{-12} \times \exp \left(\frac{-490}{T}\right)\end{array}$ \\
\hline $\begin{array}{l}\mathrm{BPI}+\mathrm{OH} \rightarrow 0.07 \mathrm{BiA} 0 \mathrm{D}+0.08 \mathrm{BiA} 1 \mathrm{D}+0.06 \mathrm{BiA} 2 \mathrm{D}+0.27 \mathrm{NOPINONE}+\mathrm{OH} \\
\mathrm{BPI}+\mathrm{O}_{3} \rightarrow 0.09 \mathrm{BiA} 0 \mathrm{D}+0.022 \mathrm{BiA} 3 \mathrm{D}+0.045 \mathrm{BiA} 2 \mathrm{D}+0.20 \mathrm{BiA} 1 \mathrm{D}+0.17 \mathrm{NOPINONE}+\mathrm{O}_{3} \\
\mathrm{BPI}+\mathrm{NO}_{3} \rightarrow 0.02 \mathrm{BiA} 0 \mathrm{D}+0.21 \mathrm{BiNIT}+0.02 \mathrm{NOPINONE}+\mathrm{NO}_{3}\end{array}$ & $\begin{array}{l}2.38 \times 10^{-11} \times \exp \left(\frac{357}{T}\right) \\
1.50 \times 10^{-17} \\
2.51 \times 10^{-12}\end{array}$ \\
\hline $\begin{array}{l}\mathrm{LIM}+\mathrm{OH} \rightarrow 0.35 \mathrm{BiA} 0 \mathrm{D}+0.15 \mathrm{BiA} 2 \mathrm{D}+\mathrm{OH} \\
\mathrm{LIM}+\mathrm{O}_{3} \rightarrow \mathrm{LIMO} 3 \mathrm{RAD}+\mathrm{O}_{3} \\
\mathrm{LIMO} 3 \mathrm{RAD}+\mathrm{HO}_{2} \rightarrow 0.14 \mathrm{BiA} 3 \mathrm{D}+0.44 \mathrm{BiA} 2 \mathrm{D}+0.42 \mathrm{BiA} 1 \mathrm{D}+\mathrm{HO}_{2} \\
\mathrm{LIMO} 3 \mathrm{RAD}+\mathrm{NO} \rightarrow 0.14 \mathrm{BiA} 3 \mathrm{D}+0.5 \mathrm{BiA} 2 \mathrm{D}+0.36 \mathrm{BiA} 1 \mathrm{D}+\mathrm{NO} \\
\mathrm{LIM}+\mathrm{NO}_{3} \rightarrow 0.69 \mathrm{BiA} 0 \mathrm{D}+0.28 \mathrm{BiNIT}+\mathrm{NO}_{3}\end{array}$ & $\begin{array}{l}4.20 \times 10^{-11} \times \exp \left(\frac{401}{T}\right) \\
2.95 \times 10^{-15} \times \exp \left(\frac{783}{T}\right) \\
4.10 \times 10^{-13} \times \exp \left(\frac{790}{T}\right) \\
8.8 \times 10^{-13} \times \exp \left(\frac{180.2}{T}\right) \\
1.22 \times 10^{-11}\end{array}$ \\
\hline
\end{tabular}

* Oxidants may be present as both reactants and products so that a reaction added to RACM2 will not affect the original photochemical oxidant concentrations. $\mathrm{MO}_{2}$ and $\mathrm{ACO}_{3}$ are the methyl peroxy radical and the peroxyacetyl radical respectively. A is either $\mathrm{NO}, \mathrm{NO}_{3}, \mathrm{MO}_{2}$ or $\mathrm{ACO}_{3}$.

tion, unfavored by humid conditions. It is represented by either a simple "reduced" reaction (or "bulk oligomerization") or an extended representation. For the extended representation, each of the oligomerization steps (each combination up to the formation of tetramer) is represented:

$$
\begin{aligned}
& A+A \underset{k_{\text {reverse, extended }}}{\stackrel{k_{\text {oligo, extended }}}{\rightleftarrows}} A_{\text {dimer }} \\
& A+A_{\text {dimer }} \underset{k_{\text {reverse, extended }}}{k_{\text {oligo, extended }}} A_{\text {trimer }} \\
& A+A_{\text {trimer }} \underset{k_{\text {reverse, extended }}}{k_{\text {oligo, extended }}} A_{\text {tretramer }} \\
& A_{\text {dimer }}+A_{\text {dimer }} \underset{k_{\text {reverse, extended }}}{k_{\text {oligo, extended }}} A_{\text {tretramer }},
\end{aligned}
$$

where $A$ is a monomer compound, $A_{\text {dimer }}$ is the dimer, $A_{\text {trimer }}$ is the trimer of compound $A$ and $A_{\text {tretramer }}$ the tetramer of compound $A, k_{\text {oligo, extended }}$ is the forward kinetic of oligomerization and $k_{\text {reverse, extended }}$ is the reverse kinetic of oligomerization. In the case of a mixture of several compounds, each combination and each product would need to be represented. The same values of $k_{\text {oligo, extended }}$ and $k_{\text {reverse, extended }}$ are used for each steps. If more data were available, the parameterization could be improved to take different kinetic rate parameters of oligomerization per combination into account. The forward kinetic of oligomerization can be linked to the reverse kinetic of oligomerization via the oligomerization equilibrium constant:

$\frac{k_{\text {oligo, extended }}}{k_{\text {reverse, extended }}}=\frac{\left(K_{\text {oligo }}^{\mathrm{eq}}\right)}{\left(a_{\mathrm{H}_{2} \mathrm{O}}\right)}$.

For the reduced (or bulk oligomerization) parameterization, all the steps are described by a single reaction:

$$
A \underset{k_{\text {reverse }}}{\stackrel{k_{\text {oligo }}}{\rightleftarrows}} \frac{1}{m_{\text {oligo }}} A_{\text {oligo }},
$$

where $A$ is a monomer compound, $A_{\text {oligo }}$ is the monomer blocks of compound $A$ inside oligomers, $m_{\text {oligo }}$ is the number of monomer blocks inside oligomers, $k_{\text {oligo }}$ is the kinetic rate parameter of oligomerization and $k_{\text {reverse }}$ is the kinetic rate parameter of the reverse reaction. In this parameterization, oligomers are represented by a single model species. $A$ represents the monomer and $A_{\text {oligo }}$ any monomer blocks present inside the oligomers. It can be use to represent oligomerization in a mixture of compounds (for example a mixture of compounds $A$ and $B$ ). If a monomer block from a compound $A$ reacts with another monomer block (the same compound $A$ or another compound $B$ ), the compound will be converted from monomer $A$ to oligomer $A_{\text {oligo }}$ (independently of the reaction with $A$ or $B$ ). The parameterization currently does not take different kinetic rate parameters between each combination of compounds into account due to lack of data. It assumes that a compound $A$ reacting with itself and a compound $B$ reacting with itself will have the same kinetic parameter and will have the same value when compounds $A$ and $B$ react together. If more data were available, the param- 
eterization could be improved to take different kinetic rate parameters of oligomerization per combination into account.

In this study, the net flux of oligomerization $J_{\text {oligo }}$ is computed using activities. Activity is often seen as the "apparent concentration" of a compound in thermodynamics. It is linked to the chemical potential (molar Gibbs free energy of a particular component) by the following equation:

$a_{i}=\exp \left(\frac{\mu_{i}-\mu_{i}^{0}}{\mathrm{R} T}\right)$,

where $a_{i}$ is the activity of compound $i, \mu_{i}$ is the chemical potential of compound $i, \mu_{i}^{0}$ is the chemical potential under standard conditions, $\mathrm{R}$ is the gas constant and $T$ is the thermodynamic temperature.

Activities (calculated here on the mole fraction basis) are used instead of concentrations for two main reasons. First, chemical rates are more consistent with thermodynamic equilibrium by computing rates using activities. For example, in the case of a simple one product $(A)$ giving one product $(B)$ equilibrium reaction, if chemical reactions are written using concentrations, the net flux of reaction $J$ would be computed with the following equation:

$J=k_{1} C_{A}-k_{-1} C_{B}$,

where $k_{1}$ is the forward kinetic parameter, $k_{-1}$ is the reverse kinetic parameter, $C_{A}$ is the concentration of compound $A$ and $C_{B}$ is the concentration of compound $B$. At equilibrium, $J$ would be equal to zero and the equilibrium constant would then correspond to the ratio of concentrations instead of a ratio of activities. This paradox can be lifted by using activities instead of concentrations. Second, some studies (Madon and Iglesia, 2000; Rahimpour, 2004) expressed the need to compute chemical rates using activities and showed that better results are obtained for nonideal systems.

The net flux of oligomerization $\mathrm{J}_{\text {oligo }}$ for the reduced parameterization (Eq. 3) is therefore computed with the following equations:

$$
\begin{aligned}
& J_{\text {oligo }}=-\frac{\mathrm{d} X_{a}, \text { monomer }}{\mathrm{d} t} \\
& =k_{\text {oligo }} a_{a, \text { monomer }}-k_{\text {reverse }} a_{a, \text { oligomer }}
\end{aligned}
$$

where $X_{a}$,monomer is the molar fraction of compound $a$, $a_{a \text {, monomer }}$ is the activity of compound $a$ on a molar fraction basis and $a_{a, \text { oligomer is the activity of the oligomer formed }}$ from compound $a$ on a molar fraction basis. Activities are computed with the AIOMFAC model (Zuend et al., 2008, 2011; Zuend and Seinfeld, 2012; Ganbavale et al., 2015).

The kinetic rate of oligomerization $k_{\text {oligo }}$ is computed as follows:

$k_{\text {oligo }}=k_{\text {oligo }}^{\max } a_{\text {monomer }}$,

where $k_{\text {oligo }}^{\max }$ is the maximum kinetic rate parameter for oligomerization and $a_{\text {monomer }}$ is the sum of monomer activities.
To calculate the reverse kinetic rate parameter, the computation is based on the equilibrium oligomerization constant $K_{\text {oligo }}^{\mathrm{eq}}$. The equilibrium constant for oligomerization (due to esterification or a similar oligomerization mechanism) is computed with

$$
\left(K_{\text {oligo }}^{\mathrm{eq}}\right)^{m_{\text {oligo }}-1}=\frac{a_{a, \text { oligomer }}\left(a_{\mathrm{H}_{2} \mathrm{O}}\right)^{m_{\text {oligo }}-1}}{a_{a, \text { monomer }}\left(a_{\text {monomer }}\right)^{m_{\text {oligo }}-1}},
$$

where $a_{\mathrm{H}_{2} \mathrm{O}}$ is the activity of water on a molar basis.

At equilibrium, the rate of oligomerization is zero. Therefore,

$$
\begin{aligned}
\frac{k_{\text {oligo }}^{\text {max }}}{k_{\text {reverse }}} & =\frac{a_{a, \text { oligomer }} / m_{\text {oligo }}}{a_{\text {monomer }} a_{a, \text { monomer }}} \\
& =\frac{\left(K_{\text {oligo }}^{\text {eq }}\right)^{m_{\text {oligo }}-1}\left(a_{\text {monomer }}\right)^{m_{\text {oligo }}-2}}{\left(a_{\mathrm{H}_{2} \mathrm{O}}\right)^{m_{\text {oligo }}-1}} .
\end{aligned}
$$

To represent oligomerization, $k_{\text {oligo }}^{\mathrm{max}}, m_{\text {oligo }}$ and $K_{\text {oligo }}^{\mathrm{eq}}$ were estimated based on the results of Kalberer et al. (2006). In their study, the molar masses of heavy molecules in SOA from several precursors were measured using matrix-assisted laser desorption-ionization mass spectrometry (MALDIMS). To represent oligomerization, we represented the formation of oligomers up to tetramers from a single monomer explicitly using the extended parameterization (Eq. 1) to simulate the evolution of mass averaged molar mass of oligomers (which cannot be simulated with our reduced parameterization (Eq. 3) for oligomerization because the molar mass of oligomers does not vary with this parameterization). The equilibrium constant of oligomerization $K_{\text {oligo }}^{\mathrm{eq}}$ and the oligomerization constant $k_{\text {oligo, extended }}$ of the extended parameterization (Eqs. 1 and 2) were fitted so that the evolution as a function of time of the weight average molar mass of oligomers during the first hours of the experiment is reproduced by the model as shown by Fig. 1. A molar mass of the TMB SOA monomer of $155 \mathrm{~g} \mathrm{~mol}^{-1}$ was chosen so that the molar mass of TMB SOA is between 140 and $170 \mathrm{~g} \mathrm{~mol}^{-1}$ based on Im et al. (2014). $m_{\text {oligo }}$ and $k_{\text {oligo }}^{\max }$ are chosen so that the molar averaged mean molar mass and the total mass of oligomers (with oligomers and monomers) of the reduced (Eq. 3) and the extended (Eq. 1) parameterizations were similar. The reduced parameterization values (Eq. 3) found for $k_{\text {oligo }}^{\max }, m_{\text {oligo }}$ and $K_{\text {oligo }}^{\mathrm{eq}}$ were respectively $2.2 \times 10^{-4} \mathrm{~s}^{-1}, 3.35$ and 2.94 for TMB SOA. $k_{\text {oligo }}^{\max }$ is in the same order of magnitude as the kinetic rate parameter reported for the reaction acetaldehyde and methanol by Roldin et al. (2014), $4.9 \times 10^{6} a\left[\mathrm{H}^{+}\right] \mathrm{M} \mathrm{h}^{-1}\left(a\left[\mathrm{H}^{+}\right]\right.$being the activity of $\mathrm{H}^{+}$), which should be around $6 \times 10^{-4} \mathrm{~s}^{-1}$ on an activity basis for a $\mathrm{pH}$ of 4.6 (order of magnitude of $\mathrm{pKa}$ for carboxylic acids). Equation (3) could also be used to take the oligomerization inside an aqueous acidic phase into account if the effect of acidity is taken into account. Based on a $\mathrm{pH}$ 

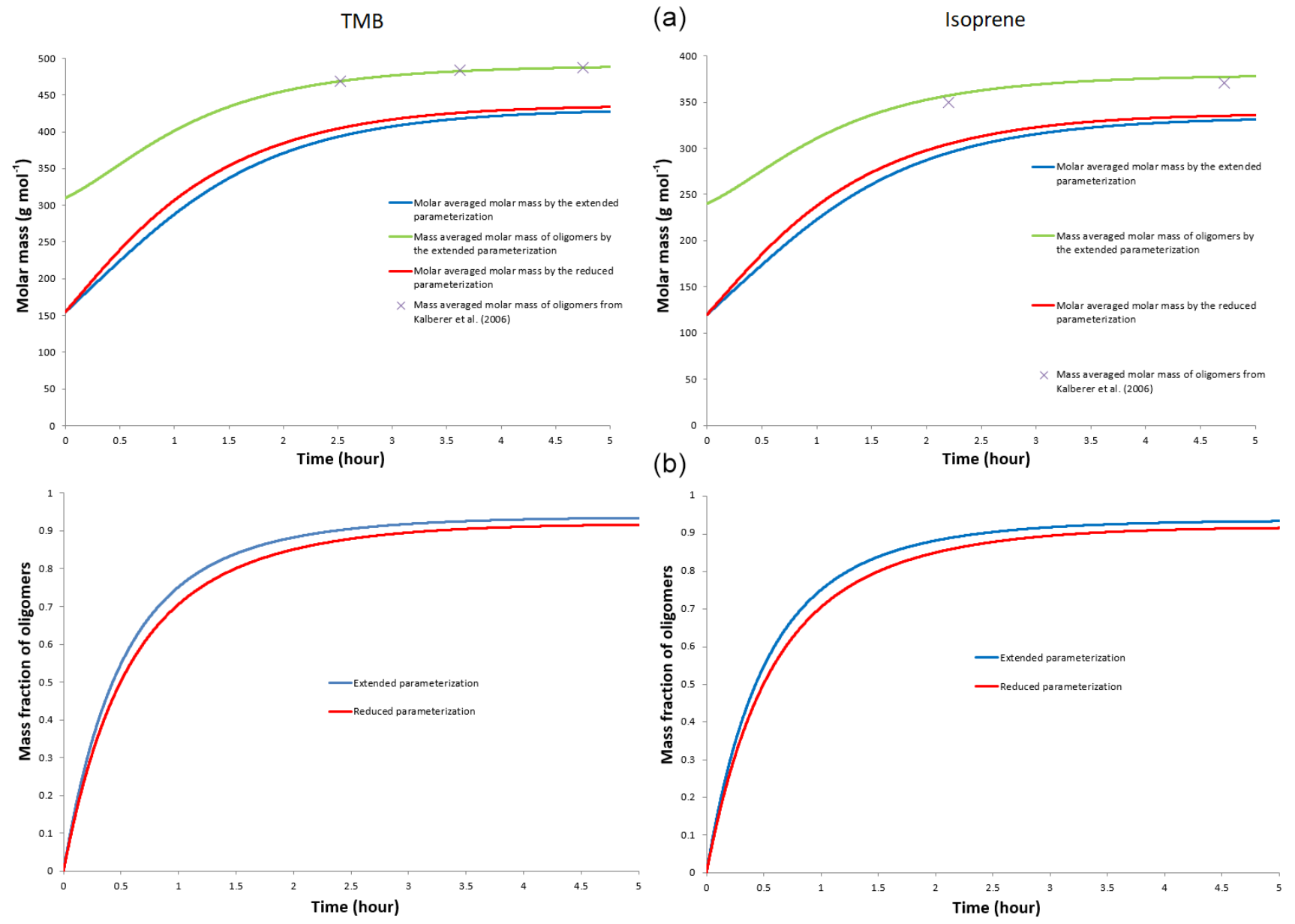

Figure 1. Temporal evolution of molar masses (a) and of the mass fraction of oligomer (b) for the extended (Eq. 1) and reduced (Eq. 3) parameterizations.

of 4.6, a kinetic rate of $8.76 a\left[\mathrm{H}^{+}\right]$(instead of $k_{\text {oligo }}^{\max }$ in Eq. 3) should be used to take the effect of acidity on oligomerization into account.

This reduced parameterization (Eq. 3) only takes the formation of short oligomers (oligomers of two to four monomer blocks that can be formed quickly during the first hours) into account but should give a good insight into the impact of oligomerization on SOA formation. Formation of short oligomers can impact SOA formation by transforming monomers and increasing the condensation of semi-volatile compounds onto the particle. However, the formation of big oligomers (more than four blocks of monomers) should affect SOA formation less as it should mainly lead to the transformation of oligomers into bigger oligomers (oligomers with higher molar masses). Big oligomers could affect the partitioning of monomers indirectly by increasing the mean molar mass of the organic phase, the partitioning constant of monomers being inversely proportional to the mean molar mass.
This parameterization also gives good results for the isoprene SOA oligomerization using a molar mass of $120 \mathrm{~g} \mathrm{~mol}^{-1}$. This molar mass corresponds to the molar mass of methyl glyceric acid, which was shown to undergo oligomerization by esterification. For $\alpha$-pinene, Kalberer et al. (2006) did not find any significant temporal evolution of oligomer molar masses, which is consistent with the formation of dimers that cannot react further and therefore parameters for oligomerization of $\alpha$-pinene SOA cannot be evaluated.

The results for SOA oligomerization from TMB and isoprene for the extended (Eq. 1) and reduced parameterizations (Eq. 3) are shown in Fig. 1. For the formation of dimers from $\alpha$-pinene, we used the same parameters except that $m_{\text {oligo }}$ is set to two to limit the formation of oligomers to dimers. DePalma et al. (2013) confirmed that particle-phase dimer formation is possible. However, Kristensen et al. (2014) studied the formation of four dimers and determined that those four dimers are not formed from particle-phase reaction but through gas-phase reactions of the stabilized Criegee inter- 
mediate formed from the ozonolysis of $\alpha$-pinene. It could then be possible that in the case of $\alpha$-pinene not all the oligomers are formed via particle-phase reactions.

In this study, the second-order reduced parameterization (Eq. 3) was used for simulations.

\subsubsection{Uptake of pinonaldehyde onto acidic aerosols}

Several studies (Liggio and Li, 2006a, b) reported an uptake of pinonaldehyde onto acidic aerosols higher than what could be predicted by assuming equilibrium between the gas and particle phases and no chemical reaction inside the particles. This phenomenon is attributed to oligomer and/or organosulfate formation. Gao et al. (2004b) reported a similar phenomenon for various aldehydes. To represent this phenomenon, Pun and Seigneur (2007) developed a parameterization by computing an effective Henry's law constant $H_{\text {eff }}$ for aldehyde compounds:

$H_{\text {eff }}=H\left(1+0.1\left(\frac{a\left(\mathrm{H}^{+}\right)}{10^{-6}}\right)^{1.91}\right)$,

where $H$ is the monomer Henry's law constant of the compound and $a\left(\mathrm{H}^{+}\right)$is the activity of protons in the aqueous phase. As fine particles are generally very acidic (Ludwig and Klemm, 1990; Keene et al., 2004), uptake of pinonaldehyde will in fact appear to be an irreversible process, even though the parameterization is formulated as a reversible process. Using this parameterization for pinonaldehyde in 3-D air quality models leads to very high concentrations of SOA from monoterpenes (Couvidat et al., 2012).

However, this parameterization does not take the uptake

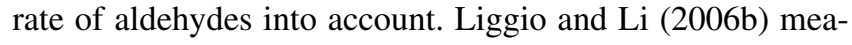
sured the uptake rate coefficients for various acidities of the aerosols. The authors showed that the uptake of pinonaldehyde onto aerosols can only be significant for very high acidities (which can be reached with low ammonia concentration and at low humidities). Based on these results, a parameterization for the chemical evolution of pinonaldehyde has been developed in this study:

$\mathrm{BiA} 0 \mathrm{D}_{\text {part }} \stackrel{k_{\text {trans }}}{\longrightarrow}$ non-volatile products,

where BiA0D is the surrogate species used by Couvidat et al. (2012) to represent pinonaldehyde, BiA0D $D_{\text {part }}$ is the amount of pinonaldehyde inside the particle and $k_{\text {trans }}\left(\right.$ in s$^{-1}$ ) is the kinetic rate of BiA0D transformation inside the particle into a product assumed non-volatile. Liggio and $\mathrm{Li}$ (2006b) did not evaluate a kinetic rate of pinonaldehyde transformation inside the particle but measured a kinetic rate of uptake. However, the kinetic parameter of uptake $k_{\text {uptake }}$ can be linked to the kinetic parameter of transformation $k_{\text {trans }}$ by assuming equilibrium between the gas and particle phases:

$k_{\text {uptake }}=k_{\text {trans }} K_{\text {aq }} \mathrm{AQ}$, where $K_{\mathrm{aq}}$ is the partition coefficient of pinonaldehyde between the gas phase and the particle and AQ is the particle mass.

As in Liggio and $\mathrm{Li}$ (2006b), the $\mathrm{pH}$ of particles and activities of compounds was computed with AIOMFAC (Zuend et al., 2008, 2011; Zuend and Seinfeld, 2012; Ganbavale et al., 2015) depending on the conditions (humidity, temperature, concentrations, etc.) of the experiments of Liggio and $\mathrm{Li}$ (2006b). The estimated flux of transformation based

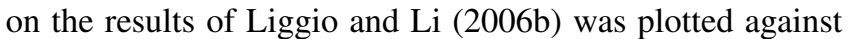
several variables to find the variables exhibiting the best correlations. $m_{\mathrm{H}^{+}}$, the molality of ion $\mathrm{H}^{+}$, and $a_{\mathrm{HSO}_{4}^{-}}^{(m)}$, the activity of ion $\mathrm{HSO}_{4}^{-}$on a molality basis, were found to be the best variables with high correlation coefficients ( 0.98 for $m_{\mathrm{H}^{+}}$and 0.92 for $a_{\mathrm{HSO}_{4}^{-}}^{(m)}$, with the kinetic of transformation pinonaldehyde $k_{\text {trans }}$ inside the particle. Figure 2 shows $k_{\text {trans }}$ (in s${ }^{-1}$ ) as a function of $m_{\mathrm{H}^{+}}\left(\mathrm{in} \mathrm{mol} \mathrm{kg}{ }^{-1}\right.$ ) and $a_{\mathrm{HSO}_{4}^{-}}^{(m)}$ (in mol kg-1).

Two possible parameterizations can therefore be used to take the possible transformation of pinonaldehyde in the particle phase into account: the $\mathrm{pH}$-dependent parameterization and the $\mathrm{HSO}_{4}^{-}$-dependent parameterization. For the $\mathrm{pH}$ dependent parameterization, the kinetic rate is computed as

$k_{\text {trans }}=2.01 \times 10^{-7} \times \exp \left(0.297 m_{\mathrm{H}^{+}}\right)$,

whereas the $\mathrm{HSO}_{4}^{-}$-dependent parameterization is computed with

$k_{\text {trans }}=1.53 \times 10^{-7} a_{\mathrm{HSO}_{4}^{-}}^{(m)}$.

In that case, we assumed that the reaction leads to the formation of the organosulfate formed from pinonaldehyde. The reaction is assumed to be complete as according to the parameterization of Pun and Seigneur (2007); the uptake of pinonaldehyde onto an acidic aerosol should be an irreversible process.

The pH-dependent parameterization (Eq. 13) could be representative of an oligomerization mechanism catalyzed by a $\mathrm{H}^{+}$ion. However, in that case, the uptake of pinonaldehyde should be seen as a reversible pathway, which also depends on the humidity of the experiments. The $\mathrm{HSO}_{4}^{-}$dependent parameterization (Eq. 14) could be representative of organosulfate formation, and therefore pinonaldehyde should in that case act as a sink for sulfates due to the reaction between sulfates and pinonaldehyde.

\subsection{Aging mechanism}

To test the influence of aging on SOA formation, an aging mechanism was developed. The aging of BiA0D is based on the results of Chacon-Madrid and Donahue (2013) who studied SOA formation from pinonaldehyde oxidation. SOA formation from BiA1D is based on the SOA yield from the oxidation of pinonic acid as measured by Müller et al. (2012). 

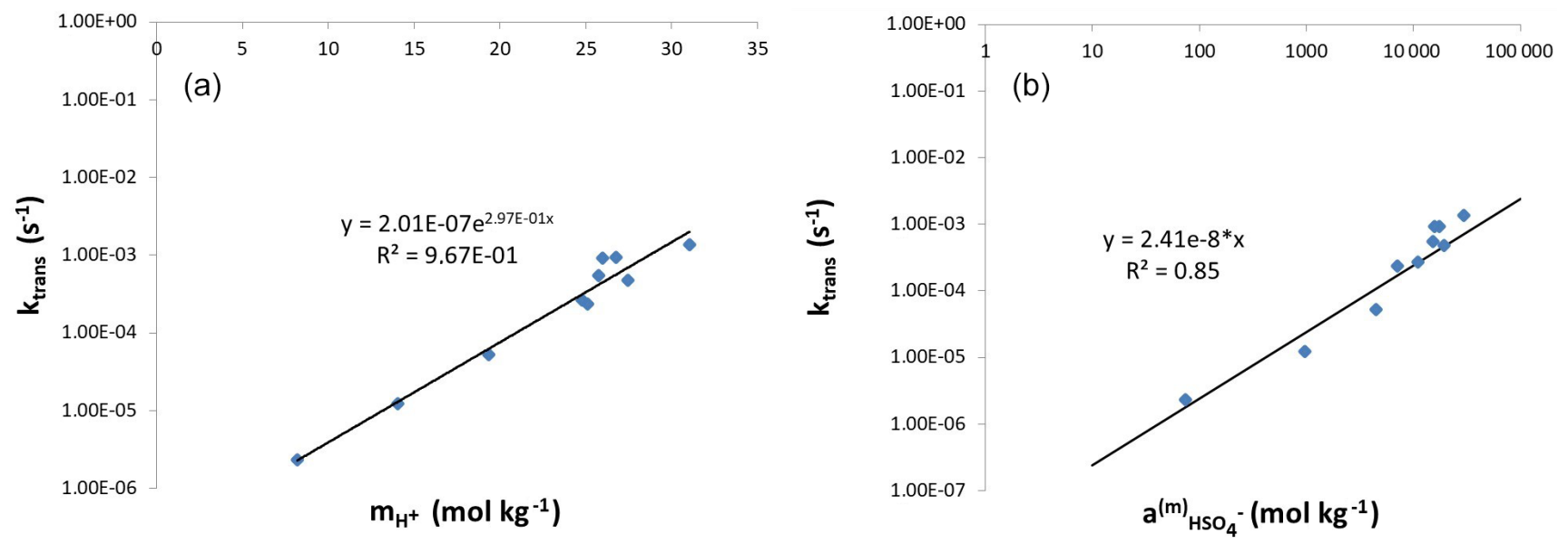

Figure 2. Kinetic rate of transformation of pinonaldehyde as a function of $m_{\mathrm{H}^{+}}$, the molality of ion $\mathrm{H}^{+}(\mathbf{a})$, and $a_{\mathrm{HSO}_{4}^{-}}^{(m)}$, the activity of ion $\mathrm{HSO}_{4}^{-}$(b) on a molality basis.

Table 7. Aging mechanism of SVOCs*.

\begin{tabular}{|c|c|c|}
\hline Reaction & 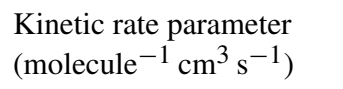 & References for used SOA yield \\
\hline $\mathrm{BiA} 0 \mathrm{D}+\mathrm{OH} \rightarrow \mathrm{RA} 0 \mathrm{D}+\mathrm{OH}$ & $9.0 \times 10^{-12}$ & - \\
\hline $\mathrm{RA} 0 \mathrm{D}+\mathrm{HO}_{2} \rightarrow \mathrm{BiA} 1 \mathrm{D}+\mathrm{HO}_{2}$ & $5.20 \times 10^{-13} \times \exp \left(\frac{980}{T}\right)$ & Chacon-Madrid and Donahue (2013) \\
\hline $\mathrm{RA} 0 \mathrm{D}+\mathrm{NO} \rightarrow 0.6 \mathrm{BiA} 1 \mathrm{D}+0.075 \mathrm{BiA} 3 \mathrm{D}+\mathrm{NO}$ & $7.50 \times 10^{-12} \times \exp \left(\frac{290}{T}\right)$ & Chacon-Madrid and Donahue (2013) \\
\hline $\mathrm{BiA} 1 \mathrm{D}+\mathrm{OH} \rightarrow 0.061 \mathrm{BiA} 3 \mathrm{D}+\mathrm{OH}$ & $1.12 \times 10^{-11}$ & Müller et al. (2012) \\
\hline $\mathrm{BiA} 2 \mathrm{D}+\mathrm{OH} \rightarrow 0.4 \mathrm{BiA} 3 \mathrm{D}+\mathrm{OH}$ & $7.29 \times 10^{-12}$ & Jathar et al. (2015) \\
\hline $\mathrm{NOPINONE}+\mathrm{OH} \rightarrow 0.16 \mathrm{BiA} 3 \mathrm{D}+\mathrm{OH}$ & $1.55 \times 10^{-11}$ & Mutzel et al. (2016) \\
\hline $\mathrm{AnRP} 1+\mathrm{OH} \rightarrow 0.26 \mathrm{AnRP} 1 \mathrm{a}+\mathrm{OH}$ & $6.0 \times 10^{-12}$ & Jathar et al. (2015) \\
\hline $\mathrm{AnRP} 2+\mathrm{OH} \rightarrow 0.06 \mathrm{AnRP} 2 \mathrm{a}+\mathrm{OH}$ & $6.0 \times 10^{-12}$ & Jathar et al. (2015) \\
\hline $\mathrm{AnIP} 1+\mathrm{OH} \rightarrow 0.04 \mathrm{AnIP} 1 \mathrm{a}+\mathrm{OH}$ & $6.0 \times 10^{-12}$ & Jathar et al. (2015) \\
\hline AnIP1a $+\mathrm{OH} \rightarrow$ Volatile products $+\mathrm{OH}$ & $6.0 \times 10^{-12}$ & Jathar et al. (2015) \\
\hline $\mathrm{AnIP} 2+\mathrm{OH} \rightarrow 0.48$ AnIP2a $+\mathrm{OH}$ & $6.0 \times 10^{-12}$ & Jathar et al. (2015) \\
\hline $\mathrm{AnIP} 2 \mathrm{a}+\mathrm{OH} \rightarrow 0.38 \mathrm{AnIP} 2 \mathrm{~b}+\mathrm{OH}$ & $6.0 \times 10^{-12}$ & Jathar et al. (2015) \\
\hline
\end{tabular}

* Oxidants may be present as both reactants and products so that a reaction added to RACM2 will not affect the original photochemical oxidant concentrations. $\mathrm{MO}_{2}$ and $\mathrm{ACO}_{3}$ are the methyl peroxy radical and the peroxyacetyl radical, respectively.

For the aging of BiA2D, the parameterizations of Jathar et al. (2015) were used to determine the amount of functionalization and the decrease of volatility due to aging. Nopinone, which is formed from the oxidation of $\beta$-pinene, was shown to form a significant amount of SOA and low-volatility products (Sato et al., 2016) and was included in the mechanism. SOA yields from nopinone oxidation were based on Mutzel et al. (2016). The yields of formation of nopinone were based on Hakola et al. (1994) for the reaction of $\beta$-pinene with $\mathrm{OH}$ and $\mathrm{O}_{3}$ and on Hallquist et al. (1999) for the reaction of $\beta$-pinene with $\mathrm{NO}_{3}$. Kinetics for aging were taken from the Master Chemical Mechanism v3.3.1 (Jenkin et al., 1997; Saunders et al., 2003).

For the aging of aromatic SOA compounds, the parameterizations of Jathar et al. (2015) were used to determine the amount of functionalization and the decrease of volatility due to aging. According to this study, oxidation of aromatics should mainly lead to the addition of one oxygen atom. For simplification purposes, we assumed that aging of aromatic SOA leads to the addition of a single hydroxy group.

Table 7 shows the aging mechanism used in this study.

This simple mechanism is used here in order to be able to assess the capacity to form oligomers and the reactive uptake of pinonaldehyde in the long-term formation of SOA.

\subsection{Long-term SOA formation simulations}

The experimental conditions (low relative humidity, oxidation over a few hours, high organic mass loading) are probably very different from typical ambient conditions. To eval- 

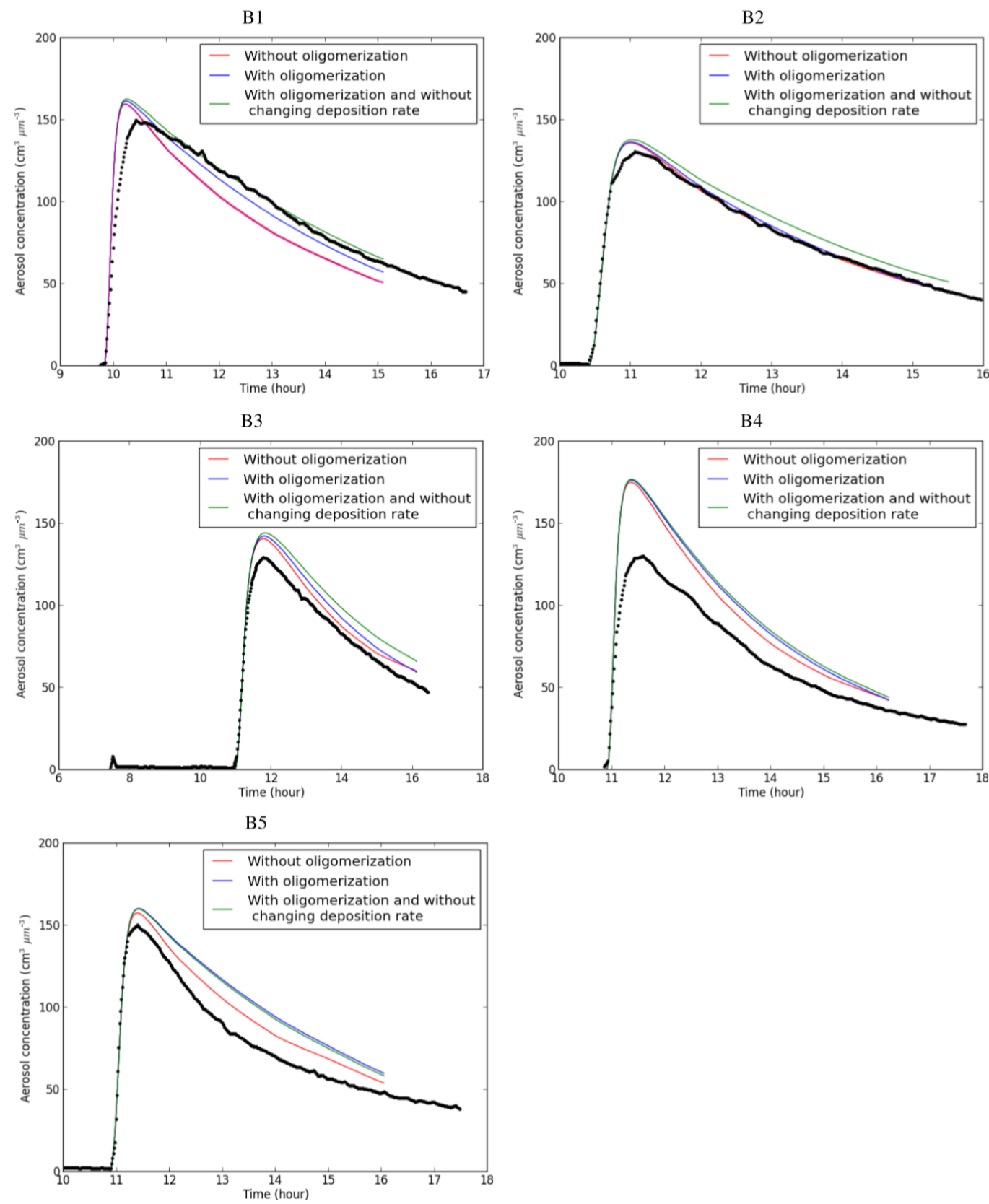

Figure 3. Aerosol concentration formation for the biogenic experiments without $\mathrm{SO}_{2}$. Black lines correspond to SMPS measurements.

uate the potential effect of oligomerization more precisely, SOA formation from the oxidation of $\alpha$-pinene, toluene and TMB over 3 days of evolution with an organic mass loading of $5 \mu \mathrm{g} \mathrm{m}^{-3}$ was simulated for various humidities with or without oligomerization. The simulated effect of oligomerization is compared to the simulated effect of aging on SOA formation. Octane and $\mathrm{NO}_{x}$ concentrations are set in order to reproduce a level of $\mathrm{OH}$ concentrations similar to summer conditions (around $0.001 \mathrm{ppb}$ during daytime). The diurnal cycle was simulated by computing the evolution of the zenith angle at Valencia, Spain, as a function of local time. This diurnal profile was simulated to take the fact into account that oxidation and aging slow down during night (due to the low concentrations of radicals), whereas oligomerization continues. On the other hand, the relative humidity was assumed constant (whereas under ambient conditions relative humidity probably has a diurnal profile). The structures of pinonic acid for simulations with $\alpha$-pinene and of AnRP2 for simulations with toluene and TMB oxidation are used for the structure of the organic loading. Those simulations 
A1

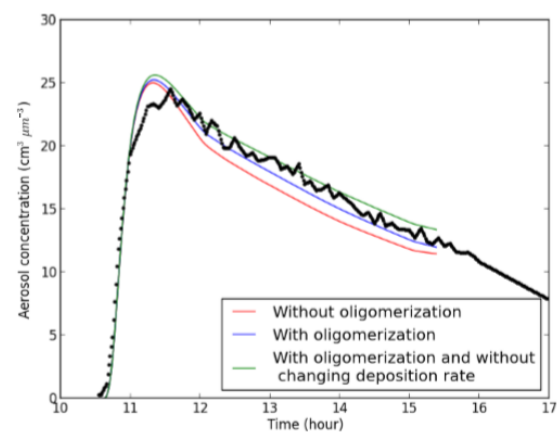

A4

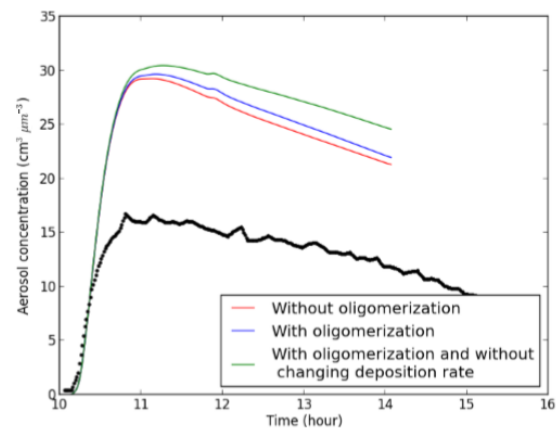

A7

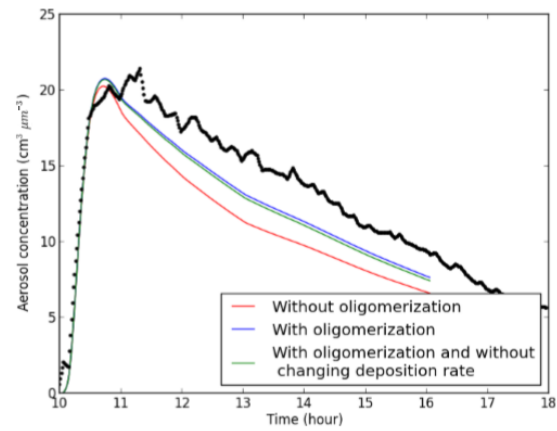

A2

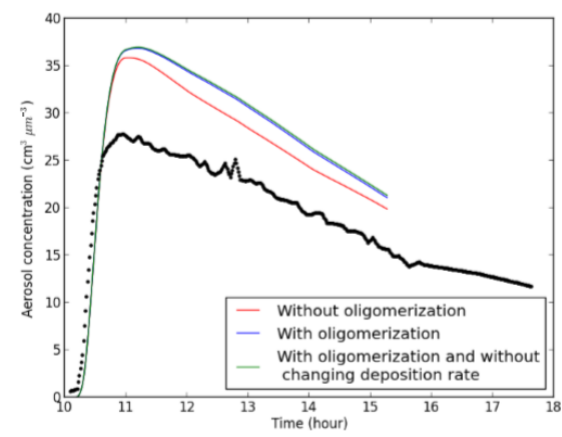

A5

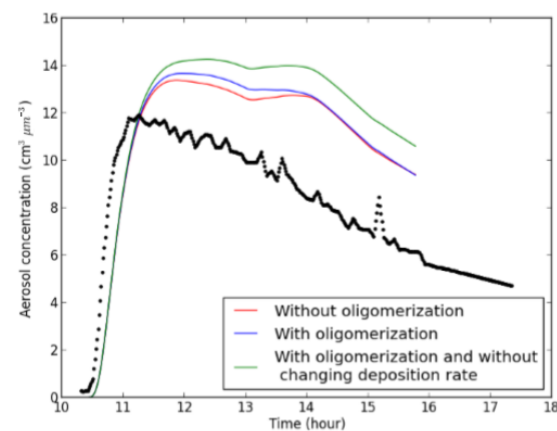

A8

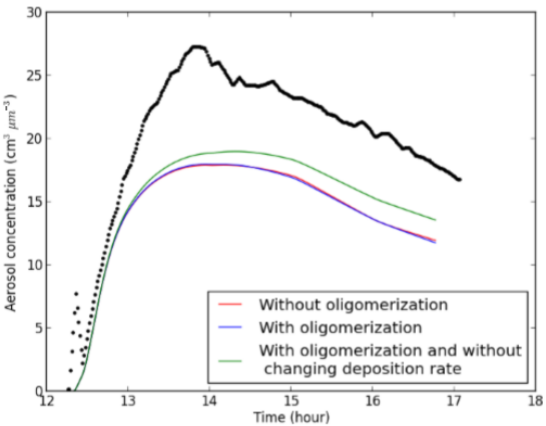

A3

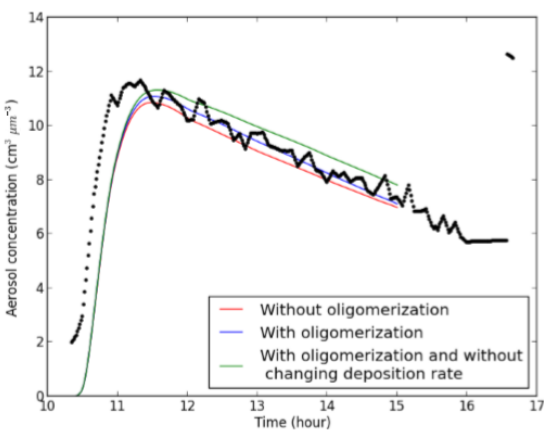

A6

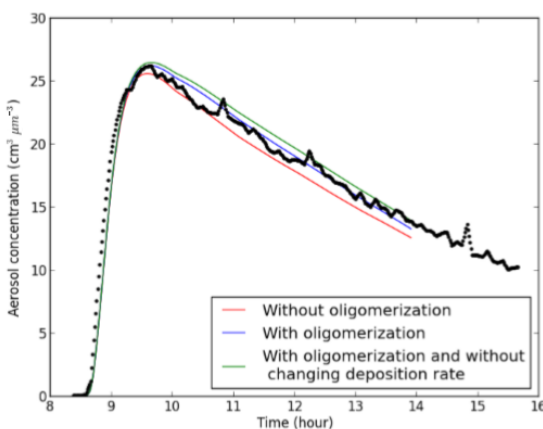

A9

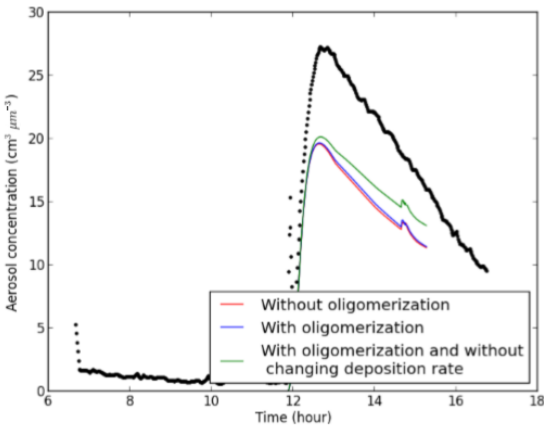

Figure 4. Aerosol concentration formation for the anthropogenic experiments. Black lines correspond to SMPS measurements.

are not representative of atmospheric conditions but can be used to illustrate the effect of long-term oligomerization on SOA formation. For simulations with oligomerization, the fraction of monomers inside the aerosol is assumed to be 1 ; i.e., the aerosol is assumed to be mainly constituted of monomers that can react with absorbed compounds. These simulations therefore provide information on the maximal effect that oligomerization can have on SOA yields.

\section{Results}

The simulated degradation of precursors is illustrated in Figs. S1 and S2 in the Supplement. Whereas the mechanism was able to reproduce the degradation of VOCs during the beginning of the experiments, medium-term oxidation of toluene seems to be underestimated for some experiments
(A1, A3, A4 and A7). Due to this, medium-term formation of toluene SOA may be underestimated.

\subsection{Comparison with measurements}

To ensure the satisfactory performances of the developed SOA mechanism under uncontrolled conditions, the results of the SOA mechanism are compared to the measurements carried out inside EUPHORE. Figures 3 and 4 show the results of the model for the biogenic experiments without $\mathrm{SO}_{2}$ and the anthropogenic experiments, respectively. Simulated SOA composition for simulations considering oligomerization is illustrated in Figs. S3 (biogenic experiments) and S4 (anthropogenic experiments).

Usually, in environmental chamber studies, the wall deposition rate is based on the evolution of concentrations during the last hours of experiments. However, in the last stage 
of the experiments, oligomerization could still occur and affect the evolution of concentrations and therefore affect the estimation of the wall deposition rate. The estimated deposition rate could be biased if the evolution of concentrations due to oligomerization at the end of the experiment is significant compared to the deposition rate. In these simulations, the wall deposition rate was constrained to reproduce with the model the decrease of SOA volume concentrations (measured with the SMPS) during the last hours of the experiments. Because the computed evolution of SOA concentrations during the last hours can be slightly different with or without oligomerization, the wall deposition rates used with and without oligomerization are different. To examine the effect of the wall deposition rate, the formation of SOA with oligomerization was also simulated with the deposition rate as computed by the simulation without oligomerization to ensure that the effects of changes on deposition remain low (changes of concentrations of a few percent) and that the hypothesis on oligomerization does not affect the estimated deposition rate.

For the biogenic experiments, the model gives good results (bias lower than $20 \%$ ) with or without oligomerization for all experiments, with slightly better results without oligomerization for experiment B5 and slightly better results with oligomerization for experiment $\mathrm{B} 1$. The experiments B2, B3, B4 and B5 have previously been modeled by Santiago et al. (2012a) using a box model version of two air quality models: CMAQ (Carlton et al., 2010) and Chimere (Menut et al., 2013). The authors found a significant overestimation of modeled SOA which was not found with the model used in this study.

For the anthropogenic experiments, the model gives satisfactory results (bias lower than 20\%) with or without oligomerization for experiment A1, A3, A6 and A7 but overestimates concentrations by $30-40 \%$ for $\mathrm{A} 2$ and $\mathrm{A} 5$ and underestimates concentrations by $25 \%$ for A8 and A9.

Concentrations for experiment A4 are overestimated by a factor of 2. However, experimental conditions for experiment A4 are close to those of experiment A1, except that HONO concentrations are 2 times higher than for experiment A4. The model gives similar results for A1 (for which the model gives satisfactory results) and A4. It could not explain why concentrations were so different between these two experiments. One possibility is that anthropogenic SOA formation is inhibited at high HONO concentrations.

The alternation of overestimation and underestimation events could be related to differences in chemical regimes. To compare the chemical regimes of the experiments, a ratio representative of the chemical regime (called hereafter "chemical regime ratio") was computed with the sum of VOC concentrations multiplied by their reactivity with $\mathrm{OH}$ divided by $\mathrm{NO}_{x}$ concentrations:

$C_{\mathrm{r}}=\frac{\sum_{i} k_{\mathrm{OH}, i} C_{i}}{C_{\mathrm{NO}_{x}}} \times 10^{10}$, where $C_{\mathrm{r}}$ is the chemical regime ratio, $C_{i}$ is the concentration of each VOC in ppb, $C_{\mathrm{NO}_{x}}$ is the concentration of $\mathrm{NO}_{x}$ in ppb and $k_{\mathrm{OH}, i}$ is the reactivity with $\mathrm{OH}$ in molecule $\mathrm{cm}^{-1} \mathrm{~s}^{-1}$; $10^{10}$ is a factor set so that the values are close to unity. The chemical regime ratio was used instead of the $\mathrm{VOC} / \mathrm{NO}_{x}$ ratio because in this study a mixture of VOCs (and not a single VOC) was present in the chamber. The chemical regime ratio takes the reactivity of the compounds into account and can therefore be used to compare different experiments with different mixtures of VOCs.

It appears that depending on the chemical regime ratio, the model may overestimate or underestimate the concentrations. Indeed, for the experiments with a low chemical regime ratio (experiments $\mathrm{A} 8$ and $\mathrm{A} 9$, which have ratios of 0.13 and 0.7, respectively) SOA concentrations are underestimated. On the contrary, SOA concentration experiments with a high chemical regime ratio (experiments A2 and A5, with ratios equal to 2.2 and 1.64 , respectively) are overestimated. Except for A4, the model gives satisfactory results for the other experiments (having chemical regime ratios between 0.77 and 1.05). It may indicate a more complex $\mathrm{NO}_{x}$ dependency than what is represented in the model.

\subsection{Effect of oligomerization on SOA formation}

For the biogenic and anthropogenic experiments, a low effect of oligomerization on SOA formation was simulated by the reduced parameterization (Eq. 3) as shown by Figs. 3 and 4. Concentrations are indeed similar with and without oligomerization with low differences compared to the amount of SOA. Although the amount of SOA does not significantly change, the composition of SOA is strongly affected by oligomerization. Indeed, the oligomer content (in mass) at the end of the experiment varies from $68 \%$ to $78 \%$ for the biogenic experiments and from $38 \%$ to $58 \%$ for the anthropogenic experiments with a similar range of humidity (between $0.4 \%$ and $37 \%$ ). For a $55 \%$ relative humidity, Gao et al. (2004a) determined for $\alpha$-pinene that the oligomer content of SOA could be well over $50 \%$. This result is consistent with the results of our parameterization as an oligomer content around $60 \%$ was simulated for such an humidity. On the contrary, for the biogenic experiments, the first-order complete oligomerization reaction of Carlton et al. (2010) with a kinetic rate parameter of $9.6 \times 10^{-6} \mathrm{~s}^{-1}$ (halftime of $20 \mathrm{~h}$ ) simulates a low number of oligomers in SOA (below $15 \%$ ). Even with the kinetic rate parameter of $3.85 \times 10^{-5} \mathrm{~s}^{-1}$ (kinetic estimated from the remaining fraction at $100^{\circ} \mathrm{C}$ measured by Kalberer et al., 2006), the number of oligomers estimated (between $29 \%$ and $40 \%$ ) is below the number estimated by the reduced parameterization (Eq. 3). These results indicate that even though the second-order reduced parameterization (Eq. 3) is not complete, it leads to a faster formation of oligomers and therefore, the parameterization of Carlton et al. (2010) may underestimate the short-term formation of oligomers. On the other hand, as the parameterization of 
Carlton et al. (2010) is complete, it may also lead to an overestimation of the long-term formation of oligomers.

The results of long-term SOA formation simulations are shown in Figs. 5, 6 and 7. Without taking aging into account, oligomerization leads to a significant increase of concentrations after 3 days of evolution, even at high humidity. Increase factors due to oligomerization are 2.5 for $\alpha$-pinene, 2.0 for toluene and 6.2 for TMB for a relative humidity of $30 \%$ and are 1.8 for $\alpha$-pinene, 1.4 for toluene and 3.3 for TMB for a relative humidity of $70 \%$. Oligomerization is therefore a process that could significantly affect long-term SOA formation.

Assuming aging leads to a slight decrease of SOA mass for toluene SOA due to fragmentation, while it leads to an increase of concentrations for TMB and $\alpha$-pinene SOA due to functionalization. However, the effect of aging on SOA formation simulated here seems less important than the effect of oligomerization.

The different parameterizations of oligomerization are also compared in Fig. 5: the equilibrium second-order reaction parameterization developed in this study, the first-order complete reaction of Carlton et al. (2010) with a kinetic rate parameter of $9.6 \times 10^{-6} \mathrm{~s}^{-1}$ (halftime of $20 \mathrm{~h}$ ) and a kinetic rate parameter of $3.85 \times 10^{-5} \mathrm{~s}^{-1}$ (halftime of $5 \mathrm{~h}$ ). The three different parameterizations have different impacts on SOA formation. The first-order parameterization with a kinetic rate parameter of $9.6 \times 10^{-6} \mathrm{~s}^{-1}$ has a low impact on SOA yields except after a few days of oligomerization. With the kinetic rate parameter of $3.85 \times 10^{-5} \mathrm{~s}^{-1}$, the increase of SOA yields can be significant after $10 \mathrm{~h}$. For $\mathrm{RH}=70 \%$ the SOA yield increases by $72 \%$ after 1 day. The second-order parameterization gives a faster SOA production. Therefore, oligomerization may be a faster process than simulated in previous modeling studies. However, this figure shows the maximal effect of the second-order parameterization (molar fraction of oligomers of 1). Depending on conditions, the second-order parameterization may only have a low impact on SOA concentrations and the formation of oligomers could rapidly reach an equilibrium.

Depending on the conditions, oligomerization could also lead to a decrease of SOA concentrations as the partitioning is inversely proportional to the mean molar mass of organic aerosols (Pankow, 1994), which will increase with the oligomer formation. Increasing the mean molar mass by a factor of 2 leads to a decrease around $40 \%$ of the SOA formed without oligomerization, indicating that the partitioning of monomers is sensitive to the value of the mean molar mass.

\subsection{Uptake of pinonaldehyde onto acidic aerosols}

The $\mathrm{pH}$ (Eq. 13) and $\mathrm{HSO}_{4}^{-}$(Eq. 14) parameterizations and the parameterization of Pun and Seigneur (2007) (Eq. 10) assuming equilibrium are compared and evaluated against experiments B6 and B7, in which $\alpha$-pinene and limonene are oxidized in the presence of $\mathrm{SO}_{2}$. The oxidation of $\mathrm{SO}_{2}$ leads to the formation of sulfuric acid and therefore to acidic aerosols. The amount of SOA formed with each parameterization is compared to the results of the experiments (Fig. 8).

The parameterization of Pun and Seigneur (2007) (Eq. 10) leads to a significant overestimation of SOA concentrations. With this parameterization, BiA0D is entirely absorbed by the acidic aerosol. On the contrary, using the $\mathrm{pH}$ (Eq. 13) and $\mathrm{HSO}_{4}^{-}$(Eq. 14) parameterizations which take the dynamic of the uptake into account, no significant formation of SOA is formed by this pathway. The two parameterizations give almost the same results as the assumption of no uptake. These results indicate that the dynamics of the uptake of pinonaldehyde need to be taken into account.

Pinonaldehyde was found to be too volatile to form significant SOA by this pathway. The long-term formation of SOA by this pathway is tested with the simulation described in the previous section but in the presence of $2 \mu \mathrm{g} \mathrm{m}^{-3}$ of sulfuric acid. Fig. 5 shows that even at low humidity $(\mathrm{RH}=30 \%)$, the amount of SOA formed is not significant after 3 days of evolution. Therefore, SOA formation from the reactive uptake by acidic aerosol of pinonaldehyde probably does not contribute significantly to SOA formation.

However, it could be possible that aldehyde compounds less volatile than pinonaldehyde react and form a significant amount of SOA by this pathway. To test this hypothesis, we assumed that organosulfate could be formed from the compounds AnRP1 and AnRP2 (which have an aldehyde group in their molecular surrogate structure) using the $\mathrm{HSO}_{4}$ parameterization (Eq. 14). The kinetic rate parameter should depend on the compound, but the $\mathrm{HSO}_{4}$ parameterization (Eq. 13) probably provides a good estimation of this phenomenon. Figure 9 shows the amount of organosulfate that would be formed by this pathway for a humidity of $70 \%$ from the oxidation of toluene. Long-term organosulfate formation seems possible by this pathway (even at high humidity) as a significant amount of organosulfate (13\% to $18 \%$ of SOA) is formed with this assumption and a significant mass of aldehydes has been converted into organosulfates. However, if high concentrations of ammonia are present in the atmosphere, $\mathrm{pH}$ will increase and $\mathrm{HSO}_{4}^{-}$will decrease. In the case of high concentrations of ammonia, the kinetic rate could be too low for this process to be significant. This process would need for sulfate to not be fully neutralized by ammonia.

\subsection{Investigation of the effect of particle-phase diffusion and wall losses of organic vapors}

To evaluate the effect of the particle-phase viscosity on SOA formation, the SOAP model was run for a particle-phase diffusion coefficient of $2 \times 10^{-16}$ molecules $\mathrm{cm}^{-2} \mathrm{~s}^{-1}$, which corresponds to the order of magnitude of values determined for toluene SOA at low humidities (Song et al., 2016). 

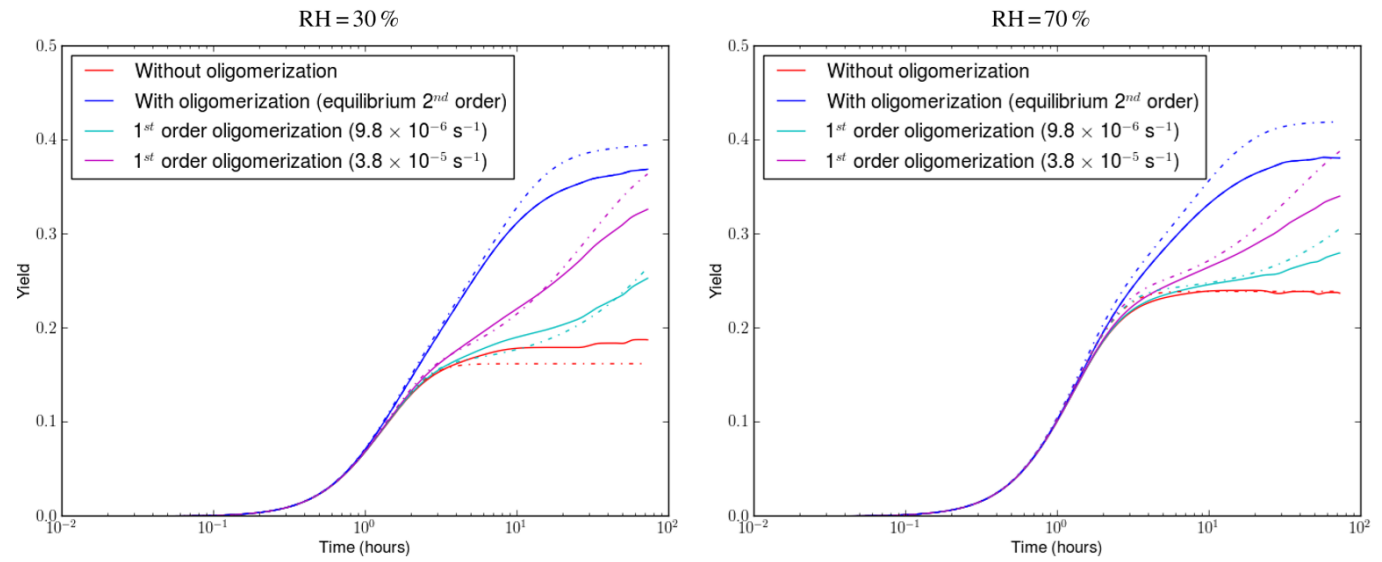

Figure 5. Evolution of the SOA yield from $\alpha$-pinene oxidation as a function of time for an organic mass loading of $5 \mu \mathrm{g} \mathrm{m}^{-3}$. Solid lines correspond to SOA formation with aging. Dashed-dotted lines correspond to SOA formation without aging.
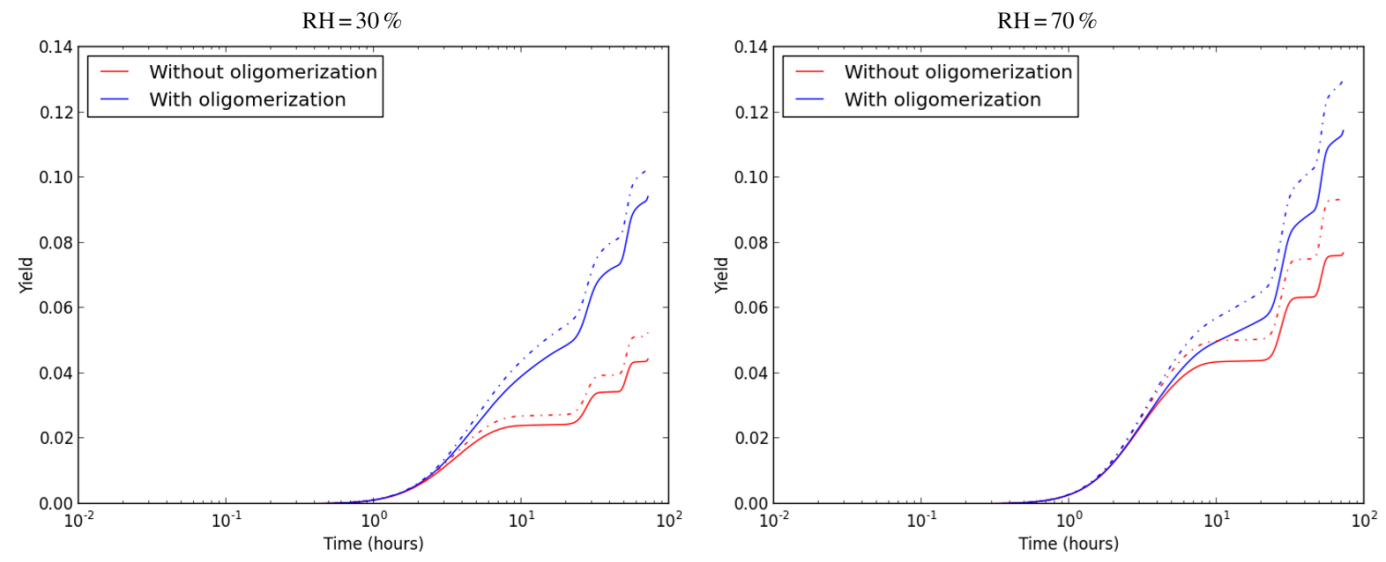

Figure 6. Evolution of the SOA yield from toluene oxidation as a function of time for an organic mass loading of $5 \mu \mathrm{g} \mathrm{m}^{-3}$. Solid lines correspond to SOA formation with aging. Dashed-dotted lines correspond to SOA formation without aging.

To investigate wall losses of organic vapors, wall losses were treated as in Zhang et al. (2014) by using a first-order wall loss rate and the organic aerosol equivalent wall (set to $10 \mathrm{mg} \mathrm{m}^{-3}$ following Zhang et al., 2014). According to McMurry and Grosjean (1985), the wall vapor loss rate $k_{\mathrm{w}}$ can be computed with the following formula:

$k_{\mathrm{w}}=\frac{A}{V} \frac{\frac{a_{\mathrm{w}} c}{4}}{1+\frac{\pi}{2} \frac{a_{\mathrm{w}} c}{4 \sqrt{k_{\mathrm{e}} D_{\mathrm{gas}}}}}$,

where $A / V$ is the surface on volume ratio of the chamber (equal to $1 \mathrm{~m}^{-1}$ for EUPHORE), $a_{\mathrm{w}}$ is the mass accommodation coefficient of organic vapors onto the wall, $c$ is the mean thermal speed of the molecules, $k_{\mathrm{e}}$ is the coefficient of eddy diffusion and $D_{\text {gas }}$ is the molecular diffusivity.

As the mixing is carried out by two fans with a flux of $4000 \mathrm{~m}^{3} \mathrm{~h}^{-1}$, the characteristic time for the mixing inside the chamber is estimated to be around $90 \mathrm{~s}$ for EUPHORE and $k_{\mathrm{w}}$ is estimated to be around $10^{-4} \mathrm{~s}^{-1}$. Following Zhang et al. (2014), the kinetic of evaporation of compounds from the wall $k_{\mathrm{w} \text {, off }}$ is computed with

$k_{\mathrm{w}, \text { off }}=\frac{k_{\mathrm{w}}}{K_{\mathrm{p}, \mathrm{w}} C_{\mathrm{w}}}$,

where $K_{\mathrm{p}, \mathrm{w}}$ is the gas-wall partition coefficient (chosen equal to the gas-particle partition coefficient) and $C_{\mathrm{w}}$ is the equivalent wall organic aerosol $(\mathrm{OA})$ concentration (set to $10000 \mu \mathrm{g} \mathrm{m}^{-3}$ ).

The effects of the particle-phase viscosity and of wall losses of vapor are illustrated in Fig. 10 for experiments A5, A7 and B1. Results for other experiments (biogenic and anthropogenic) are similar to these experiments and are illustrated in Figs. S5 and S6.

Generally, similar results are obtained between nonviscous and viscous aerosols. Assuming viscous aerosols can lead to an increase of SOA concentrations due to the limitation of evaporation with low diffusion. As found by Couvidat and Sartelet (2015), condensation of low-volatility com- 

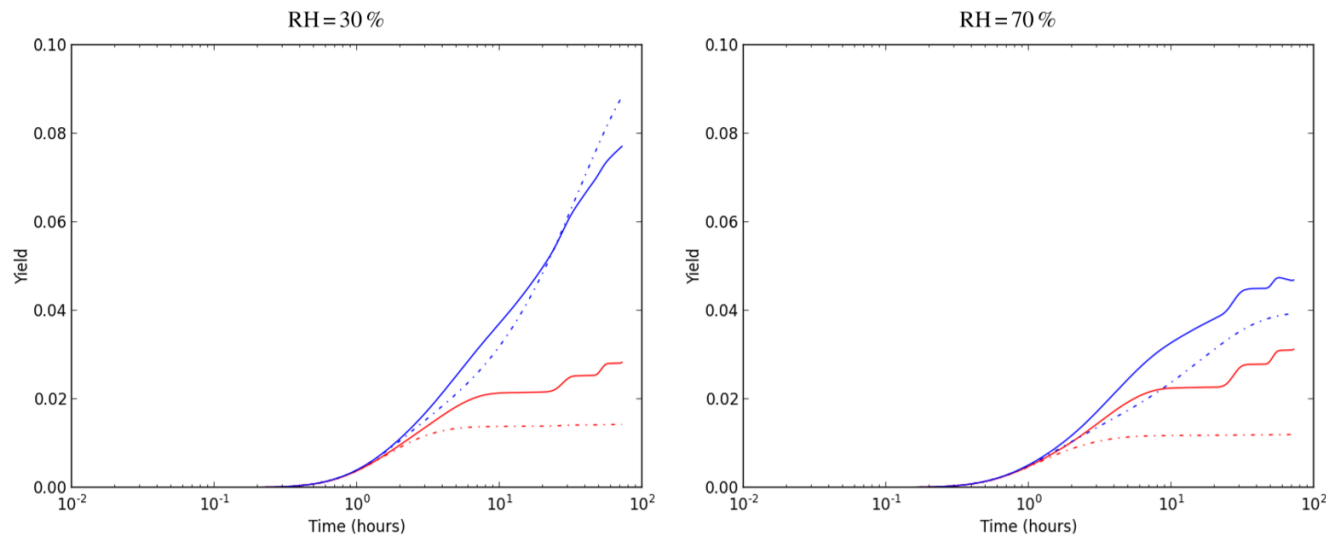

Figure 7. Evolution of the SOA yield from trimethylbenzene oxidation as a function of time for an organic mass loading of $5 \mu \mathrm{g} \mathrm{m}{ }^{-3}$. Solid lines correspond to SOA formation with aging. Dashed-dotted lines correspond to SOA formation without aging.
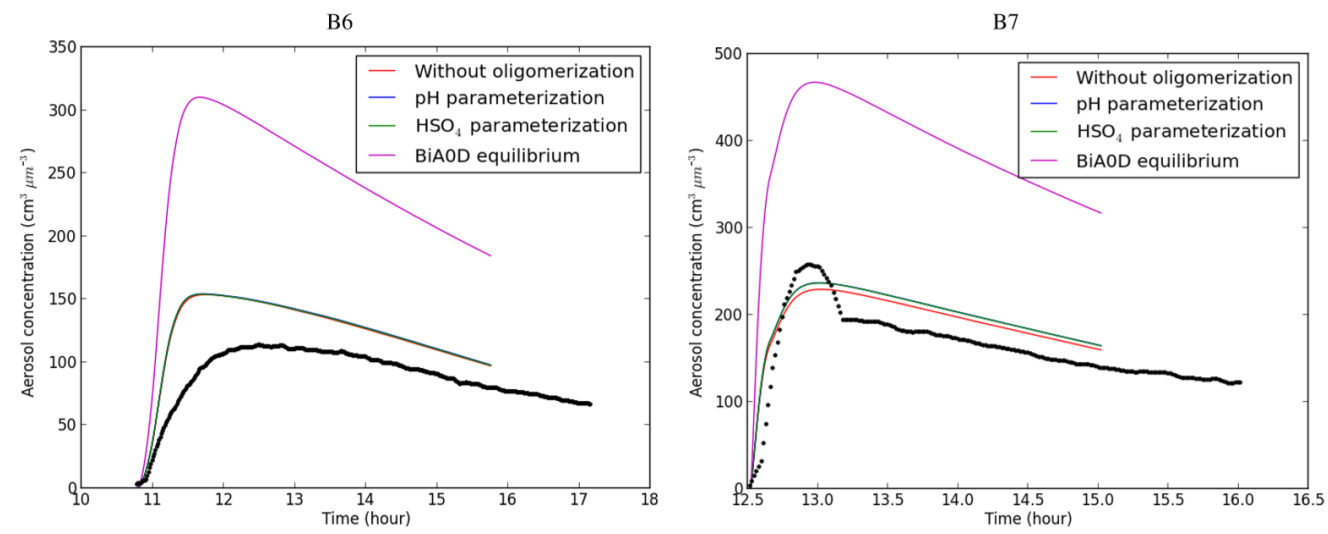

Figure 8. Aerosol concentration formation for the biogenic experiments with $\mathrm{SO}_{2}$. Black lines correspond to SMPS measurements.

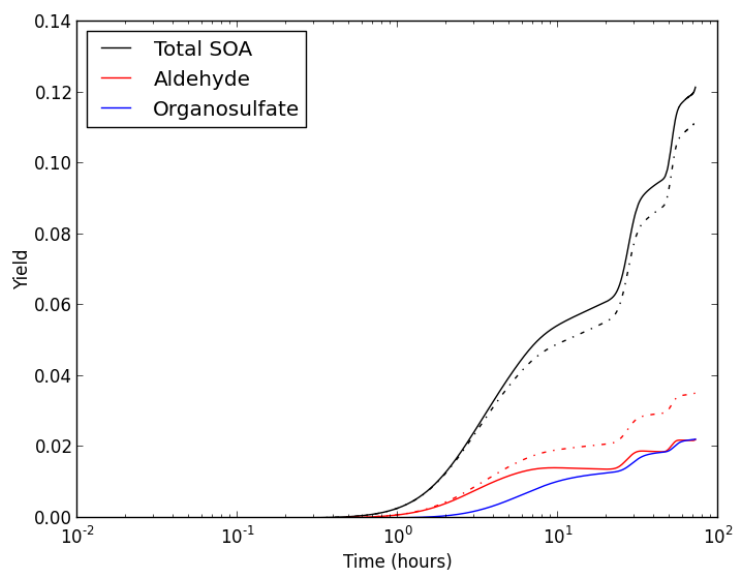

Figure 9. Yield of formation of SOA, aldehydes and organosulfates with (solid lines) or without (dashed lines) the conversion of aldehydes into organosulfates as a function of time for an organic mass loading of $5 \mu \mathrm{g} \mathrm{m}^{-3}$ with $2 \mu \mathrm{g} \mathrm{m}^{-3}$ of sulfates. pounds is possible without diffusing into the particle by condensing at the gas-particle interface. The condensation of low-volatility compounds can create a layer onto which more volatile compounds can condense to respect Raoult's law at the interface. However, viscosity can prevent the evaporation of those more volatile compounds by preventing their diffusion from the core of the particle to the interface. For non-viscous aerosols, the deposition of particles to the walls leads to a decrease of the absorbing mass (mass of the organic aerosol). As the gas-particle partitioning depends on the absorbing mass, SVOCs will evaporate to maintain the gasparticle partitioning, whereas this evaporation will be limited for a viscous aerosol.

It can be assumed that viscous aerosols can also lead to a decrease of SOA sensitivity to changes of conditions during the experiments. For example, experiment A5 is characterized by a decrease of the temperature during the experiment leading to a decrease of volatility. Whereas concentrations increase when assuming non-viscous aerosols, concentrations seem unaffected by the change of temperature when assuming viscous aerosols (as compounds are absorbed by 
A5

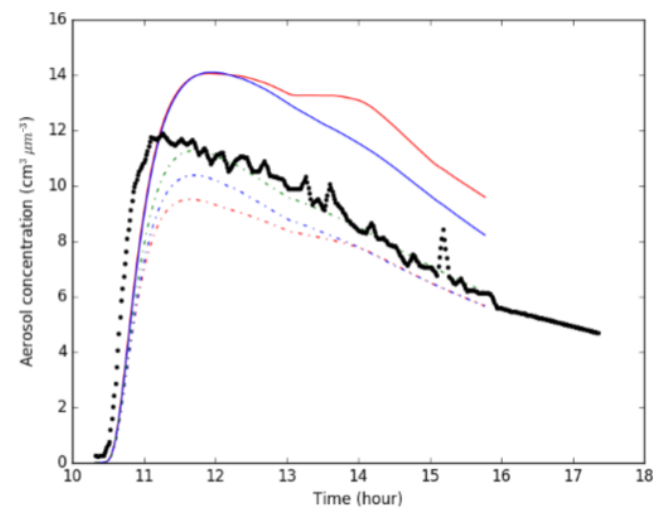

B1

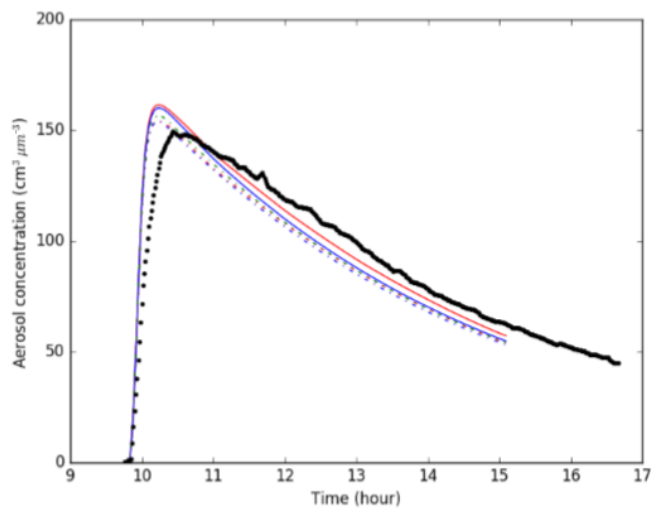

A7

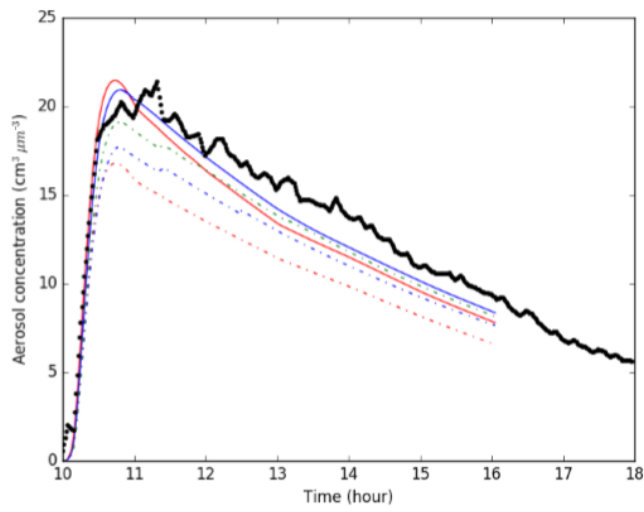

Figure 10. Effect of viscosity and gas wall losses on SOA concentrations for several experiments. The black line corresponds to SMPS measurements, the red lines correspond to modeled SOA concentrations for the non-viscous aerosol assumption, the blue lines correspond to modeled SOA concentrations for the viscous aerosol assumption and the green line corresponds to modeled SOA concentrations for the viscous aerosol assumption with a decrease by $20 \%$ of volatilities. Solid lines correspond to simulations assuming no gas wall losses, and dotted lines correspond to those assuming gas wall losses.

the core of particles with a slow kinetic rate). The shape of the modeled SOA concentration curve is closer to measurements when assuming viscous aerosols.

Taking wall losses of vapors into account leads to a decrease of SOA concentrations (as illustrated in Fig. 10), particularly for the anthropogenic experiments (decrease between $8 \%$ and $30 \%$ ) due to the lower organic aerosol loading compared to the biogenic experiments. As the developed mechanism is based on the methodology of Odum et al. (1996) by using experimental results from Teflon chambers, it could be possible that the parameters of the mechanism (saturation vapor pressures and stoichiometric coefficients for the formation of SVOCs) are biased. As stronger organic aerosol loading favors condensation onto organic aerosol over condensation onto walls, wall losses of vapor may produce a shift in apparent volatilities; the organic aerosol formed in chambers may appear more volatile than it should be. For both the biogenic and anthropogenic experiments, results can be corrected by decreasing the saturation vapor pressures by $20 \%$ as better or similar results could be obtained than without taking wall losses of organic vapors into account. These results indicate that volatility determined by the use of Odum's curves may be slightly overestimated. However, wall deposition of organic vapors could also lead to an underestimation in the SOA mechanism of stoichiometric coefficients.

\section{Conclusions}

Several parameterizations were developed in this study. First, in the spirit of updating the $\mathrm{H}^{2} \mathrm{O}$ mechanism (Couvidat et al., 2012), a new mechanism was developed to take hydrophilic and hydrophobic properties of monoterpene and aromatic SOA into account and introduce aging in the mechanism. The performance of the new mechanism was evaluated by comparison to experimental results from previous studies carried out in the EUPHORE chamber in Valencia, Spain. Second, parameterizations to take oligomerization and the uptake of pinonaldehyde onto acidic aerosols into account were devel- 
oped. Finally, the effects of particle viscosity and wall deposition of vapors were investigated.

Without taking wall losses of vapors into account, satisfactory results are obtained for the biogenic experiments. However, the experiments used for the comparison present a high organic aerosol loading (between 50 and $150 \mu \mathrm{g} \mathrm{m}^{-3}$ ), much higher than the values normally observed under atmospheric conditions. More experiments at low organic aerosol loading should be carried out to provide a wider observational dataset that could be used to evaluate model developments. A good performance is also found for most of the anthropogenic experiments. However, for the experiments with the lower chemical regime ratio (Eq. 15; product of VOC concentrations and their reactivity divided by $\mathrm{NO}_{x}$ concentrations), the model underestimates concentrations by $30 \%$, whereas for the experiments with the higher chemical regime ratio, the model overestimates concentrations by $30 \%$. This could indicate a more complex $\mathrm{NO}_{x}$ chemistry than the one taken into account in the model. However, this discrepancy could be due to the difficulty of simulating radicals inside the chamber under some conditions properly. More experiments should be carried out to confirm these results and improve the $\mathrm{NO}_{x}$ dependency inside the model.

Contrary to Carlton et al. (2010), who represented oligomerization as a first-order irreversible process, oligomerization was represented in the present study (as an effort to provide a more realistic representation) as a second-order reversible reaction unfavored by humid conditions by analogy to oligomerization reactions expected to occur in the particles, such as esterification, hemiacetalization, aldolization and peroxyhemiacetalization. With this new parameterization, oligomerization was shown to have little impact on SOA mass during the experiments. However, oligomerization was found to significantly affect SOA composition as a large part of SOA is constituted (more than $50 \%$ for the biogenic experiments) by oligomers according to the simulations. These results seem to be consistent with the high number of oligomers reported by Gao et al. (2004a). Conversely, a low number of oligomers was simulated with the parameterization of Carlton et al. (2010) (below $15 \%$ at the end of the experiments). The results of the present study with the new parameterization indicate that oligomerization may be faster than simulated by the parameterization of Carlton et al. (2010) but at the same time may reach an equilibrium. However, more effort should be given to improve this parameterization. Indeed, this parameterization represents a bulk oligomerization and does not account for differences in the reactivity of monomers. This parameterization should nonetheless be employed and tested in 3-D air quality models to diagnose the effect of oligomerization on SOA formation.

Instead of representing the uptake of pinonaldehyde by an equilibrium phenomenon (like the parameterization of Pun and Seigneur, 2007), we chose to take the kinetic of this uptake into account, which was shown to limit the uptake of pinonaldehyde strongly (Liggio and Li, 2006b). The uptake of pinonaldehyde was found to be too slow to contribute significantly to the formation of organic aerosols, suggesting that the approach of Pun and Seigneur (2007) (Eq. 10) greatly overestimates the effect of the particle acidity on SOA formation. However, it could be possible that the uptake of aldehydes less volatile than pinonaldehyde (or more reactive) is strongly influenced by the particle acidity, leading to the formation of oligomers or organosulfate.

Taking into account wall losses of organic vapors with the parameters of Zhang et al. (2014) led to a decrease of SOA concentrations of up to $30 \%$. As the mechanism developed in the present study is based on the methodology of Odum et al. (1996) by using experimental results from Teflon chambers, the parameters of the mechanism (saturation vapor pressures and stoichiometric coefficients for the formation of SVOC) could be biased. The simulated decrease of SOA concentrations could however be compensated by decreasing the volatility of SVOC by $20 \%$ (decrease of the value of saturation vapor pressures by $20 \%$ ).

Regarding RH, the model indicates that RH may strongly influence SOA yields, which is consistent with the results of Healy et al. (2009). Unfortunately, the conditions of the experiments used in this study do not cover the full range of $\mathrm{RH}$. More experiments carried out at high humidity could be used to evaluate the model performance for other humidities.

Finally, these parameterizations should be implemented in a 3-D air quality models to evaluate their impact on SOA formation in the atmosphere. Oligomerization should especially be studied in detail as it could lead either to an increase or a decrease (by increasing the mean molar mass that would lead to a decrease of the partitioning constant of monomers) of SOA concentrations.

Data availability. The data are accessible by contacting the corresponding author (florian.couvidat@ineris.fr).

\section{The Supplement related to this article is available online at: https://doi.org/10.5194/acp-18-15743-2018- supplement}

Author contributions. FC wrote the article, developed the model and simulations and analysed results. MV co-developed the model, provided the observational dataset and analysed results. BB was the initial investigator of the study and analysed results.

Competing interests. The authors declare that they have no conflict of interest.

Acknowledgements. This work was funded by the French Ministry of Ecology. 
Edited by: Barbara Ervens

Reviewed by: two anonymous referees

\section{References}

Bian, Q., May, A. A., Kreidenweis, S. M., and Pierce, J. R.: Investigation of particle and vapor wall-loss effects on controlled wood-smoke smog-chamber experiments, Atmos. Chem. Phys., 15, 11027-11045, https://doi.org/10.5194/acp-15-110272015, 2015.

Cappa, C. D., Jathar, S. H., Kleeman, M. J., Docherty, K. S., Jimenez, J. L., Seinfeld, J. H., and Wexler, A. S.: Simulating secondary organic aerosol in a regional air quality model using the statistical oxidation model - Part 2: Assessing the influence of vapor wall losses, Atmos. Chem. Phys., 16, 3041-3059, https://doi.org/10.5194/acp-16-3041-2016, 2016.

Carlton, A. G., Bhave, P. V., Napelenok, S. L., Edney, E. O., Sarwar, G., Pinder, R. W., Pouliot, G. A., and Houyoux, M.: Model Representation of Secondary Organic Aerosol in CMAQv4.7, Environ. Sci. Tech., 44, 8553-8560, https://doi.org/10.1021/es100636q, 2010.

Chacon-Madrid, H. J., Henry, K. M., and Donahue, N. M.: Photooxidation of pinonaldehyde at low $\mathrm{NO}_{x}$ : from chemistry to organic aerosol formation, Atmos. Chem. Phys., 13, 3227-3236, https://doi.org/10.5194/acp-13-3227-2013, 2013.

Cocker III, D. R., Mader, B. T., Kalberer, M., Flagan, R. C., and Seinfeld, J. H.: The effect of water on gas-particle partitioning of secondary organic aerosol: II. $m$-xylene and 1,3,5trimethylbenzene photooxidation systems, Atmos. Environ., 35, 6073-6085, https://doi.org/10.1016/S1352-2310(01)00405$8,2001$.

Couvidat, F. and Sartelet, K.: The Secondary Organic Aerosol Processor (SOAP v1.0) model: a unified model with different ranges of complexity based on the molecular surrogate approach, Geosci. Model Dev., 8, 1111-1138, https://doi.org/10.5194/gmd8-1111-2015, 2015.

Couvidat, F. and Seigneur, C.: Modeling secondary organic aerosol formation from isoprene oxidation under dry and humid conditions, Atmos. Chem. Phys., 11, 893-909, https://doi.org/10.5194/acp-11-893-2011, 2011.

Couvidat, F., Debry, É., Sartelet, K., and Seigneur, C.: A Hydrophilic/Hydrophobic Organic $\left(\mathrm{H}^{2} \mathrm{O}\right)$ model: Model development, evaluation and sensitivity analysis, J. Geophys. Res., 117, D10304, https://doi.org/10.1029/2011JD017214, 2012.

Couvidat, F., Bessagnet, B., Garcia-Vivanco, M., Real, E., Menut, L., and Colette, A.: Development of an inorganic and organic aerosol model (CHIMERE 2017 $\beta$ v1.0): seasonal and spatial evaluation over Europe, Geosci. Model Dev., 11, 165-194, https://doi.org/10.5194/gmd-11-165-2018, 2018.

DePalma, J. W., Horan, A. J., Hall IV, W. A., and Johnston, M. V.: Thermodynamics of oligomer formation: implications for secondary organic aerosol formation and reactivity, Phys. Chem. Chem. Phys., 15, 6935-6944, https://doi.org/10.1039/C3cp44586k, 2013.

Donahue, N. M., Robinson, A. L., Stanier, C. O., and Pandis, S. N.: Coupled Partitioning, Dilution, and Chemical Aging of
Semivolatile Organics, Environ. Sci. Technol., 40, 2635-2643, https://doi.org/10.1021/es052297c, 2006.

Donahue, N. M., Epstein, S. A., Pandis, S. N., and Robinson, A. L.: A two-dimensional volatility basis set: 1. organic-aerosol mixing thermodynamics, Atmos. Chem. Phys., 11, 3303-3318, https://doi.org/10.5194/acp-11-3303-2011, 2011

Fountoukis, C. and Nenes, A.: ISORROPIA II: a computationally efficient thermodynamic equilibrium model for $\mathrm{K}^{+}$ $\mathrm{Ca}^{2+}-\mathrm{Mg}^{2+}-\mathrm{NH}_{4}^{+}-\mathrm{Na}^{+}-\mathrm{SO}_{4}^{2-}-\mathrm{NO}_{3}^{-}-\mathrm{Cl}^{-}-\mathrm{H}_{2} \mathrm{O}$ aerosols, Atmos. Chem. Phys., 7, 4639-4659, https://doi.org/10.5194/acp-74639-2007, 2007.

Fry, J. L., Draper, D. C., Barsanti, K. C., Smith, J. N., Ortega, J., Winkler, P. M., Lawler, M. J., Brown, S. S., Edwards, P. M., Cohen, R. C., and Lee, L.: Secondary Organic Aerosol Formation and Organic Nitrate Yield from NO3 Oxidation of Biogenic Hydrocarbons, Environ. Sci. Technol., 48, 11944-11953, https://doi.org/10.1021/es502204x, 2014.

Ganbavale, G., Zuend, A., Marcolli, C., and Peter, T.: Improved AIOMFAC model parameterisation of the temperature dependence of activity coefficients for aqueous organic mixtures, Atmos. Chem. Phys., 15, 447-493, https://doi.org/10.5194/acp-15447-2015, 2015.

Gao, S., Keywood, M., Ng, N. L., Surratt, J., Varutbangkul, V., Bahreini, R., Flagan, R. C., and Seinfeld, J. H.: Low-Molecular-Weight and Oligomeric Components in Secondary Organic Aerosol from the Ozonolysis of Cycloalkenes and $\alpha$-pinene, J. Phys. Chem. A, 108, 10147-10164, https://doi.org/10.1021/jp047466e, 2004a.

Gao, S., Ng, N. L., Keywood, M., Varutbangkul, V., Bahreini, R., Nenes, A., He, J., Yoo, K. Y., Beauchamp, J. L., Hodyss, R. P., Flagan, R. C., and Seinfeld, J. H.: Particle phase acidity and oligomer formation in secondary organic aerosol, Environ. Sci. Technol., 38, 6582-6589, https://doi.org/10.1021/es049125k, 2004b.

Goliff, W. S., Stockwell, W. R., and Lawson, C. V.: The Regional Atmospheric Chemistry Mechanism, Version 2, Atmos. Environ., 68, 174-185, 2013.

Griffin, R. J., Nguyen, K., Dabdub, D., and Seinfeld, J. H.: A coupled hydrophobic-hydrophilic model for predicting secondary organic aerosol formation, J. Atmos. Chem., 44, 171190, https://doi.org/10.1023/A:1022436813699, 2003.

Hakola, H., Arey, J., Aschmann, S. M., and Atkinson, R.: Product formation from the gas-phase reactions of $\mathrm{OH}$ radicals and $\mathrm{O}_{3}$ with a series of monoterpenes, J. Atmos. Chem., 18, 75-102, https://doi.org/10.1007/BF00694375, 1994.

Hall IV, W. A. and Johnston, M. V.: Oligomer Content of $\alpha$ Pinene Secondary Organic Aerosol, Aerosol Sci. Tech., 45, 37 45, https://doi.org/10.1080/02786826.2010.517580, 2011.

Hallquist, M., Wängberg, I., Ljungström, E., Barnes, I., and Becher, K.-H.: Aerosol and product yield from $\mathrm{NO}_{3}$ radical-initiated oxidation of selected monoterpenes, Environ. Sci. Technol., 33, 553-559, https://doi.org/10.1021/es980292s, 1999.

Han, Z., Xie, Z., Wang, G., Zhang, R., and Tao, J.: Modeling organic aerosols over east China using a volatility basis-set approach with aging mechanism in a regional air quality model, Atmos. Environ., 124, 186-198, https://doi.org/10.1016/j.atmosenv.2015.05.045, 2016.

Healy, R. M., Temine, B., Kuprovskyte, K., and Wenger, J. C.: Effect of Relative Humidity on Gas/Particle Par- 
titioning and Aerosol Mass Yield in the Photooxidation of $p$-Xylene, Environ. Sci. Technol., 43, 1884-1889, https://doi.org/10.1021/es802404z, 2009.

Im, Y., Jang, M., and Beardsley, R. L.: Simulation of aromatic SOA formation using the lumping model integrated with explicit gas-phase kinetic mechanisms and aerosol-phase reactions, Atmos. Chem. Phys., 14, 4013-4027, https://doi.org/10.5194/acp14-4013-2014, 2014.

Jathar, S. H., Cappa, C. D., Wexler, A. S., Seinfeld, J. H., and Kleeman, M. J.: Multi-generational oxidation model to simulate secondary organic aerosol in a 3-D air quality model, Geosci. Model Dev., 8, 2553-2567, https://doi.org/10.5194/gmd-8-2553-2015, 2015.

Jathar, S. H., Cappa, C. D., Wexler, A. S., Seinfeld, J. H., and Kleeman, M. J.: Simulating secondary organic aerosol in a regional air quality model using the statistical oxidation model - Part 1: Assessing the influence of constrained multi-generational ageing, Atmos. Chem. Phys., 16, 2309-2322, https://doi.org/10.5194/acp-16-2309-2016, 2016.

Jenkin, M. E., Saunders, S. M., and Pilling, M. J.: The tropospheric degradation of volatile organic compounds: a protocol for mechanism development, Atmos. Environ., 31, 81-104, 1997.

Kalberer, M., Paulsen, D., Sax, M., Steinbacher, M., Dommen, J., Prevot, A. S. H., Fisseha, R., Weingartner, E., Frankevich, V., Zenobi, R., and Baltensperger, U.: Identification of Polymers as Major Components of Atmospheric Organic Aerosols, Science, 303, 1659-1662, https://doi.org/10.1126/science.1092185, 2004.

Kalberer, M., Sax, M., and Samburova, V.: Molecular size evolution of oligomers in organic aerosols collected in urban atmospheres and generated in a smog chamber, Environ. Sci. Technol., 40, 5917-5922, https://doi.org/10.1021/es0525760, 2006.

Kanakidou, M., Seinfeld, J. H., Pandis, S. N., Barnes, I., Dentener, F. J., Facchini, M. C., Van Dingenen, R., Ervens, B., Nenes, A., Nielsen, C. J., Swietlicki, E., Putaud, J. P., Balkanski, Y., Fuzzi, S., Horth, J., Moortgat, G. K., Winterhalter, R., Myhre, C. E. L., Tsigaridis, K., Vignati, E., Stephanou, E. G., and Wilson, J.: Organic aerosol and global climate modelling: a review, Atmos. Chem. Phys., 5, 1053-1123, https://doi.org/10.5194/acp-5-10532005, 2005.

Keene, W. C., Pszenny, A. A. P., Maben, J. R., Stevenson, E., and Wall, A.: Closure evaluation of size-resolved aerosol $\mathrm{pH}$ in the New England coastal atmosphere during summer, J. Geophys. Res., 109, D23307, https://doi.org/10.1029/2004JD004801, 2004.

Kim, H., Liu, S., Russell, J. M., and Paulson, S. E.: Dependence of Real Refractive Indices on O:C, H:C and Mass Fragments of Secondary Organic Aerosol Generated from Ozonolysis and Photooxidation of Limonene and $\alpha$-Pinene, Aerosol Sci. Tech., 48, 498-507, https://doi.org/10.1080/02786826.2014.893278, 2014.

Kim, Y., Sartelet, K., and Seigneur, C.: Comparison of two gas-phase chemical kinetic mechanisms of ozone formation over Europe, J. Atmos. Chem., 62, 82-119, https://doi.org/10.1007/s10874-009-9142-5, 2009.

Koo, B., Knipping, E., and Yarwood, G.: 1.5-Dimensional volatility basis set approach for modeling organic aerosol in CAMx and CMAQ, Atmos. Environ., 95, 158-164, https://doi.org/10.1016/j.atmosenv.2014.06.031, 2014.

Kristensen, K., Cui, T., Zhang, H., Gold, A., Glasius, M., and Surratt, J. D.: Dimers in $\alpha$-pinene secondary organic aerosol: effect of hydroxyl radical, ozone, relative humidity and aerosol acidity, Atmos. Chem. Phys., 14, 4201-4218, https://doi.org/10.5194/acp-14-4201-2014, 2014.

Lane, T. E., Donahue, N. M., and Pandis, S. N.: Simulating secondary organic aerosol formation using the volatility basisset approach in a chemical transport model, Atmos. Environ., 42, 7439-7451, https://doi.org/10.1016/j.atmosenv.2008.06.026, 2008.

Lee, B.-H., Pierce, J. R., Engelhart, G. J., and Pandis, S. N.: Volatility of secondary organic aerosol from the ozonolysis of monoterpenes, Atmos. Environ., 45, 2443-2452, https://doi.org/10.1016/j.atmosenv.2011.02.004, 2011.

Lemaire, V., Coll, I., Couvidat, F., Mouchel-Vallon, C., Seigneur, C., and Siour, G.: Oligomer formation in the troposphere: from experimental knowledge to 3-D modeling, Geosci. Model Dev., 9, 1361-1382, https://doi.org/10.5194/gmd-9-1361-2016, 2016.

Liggio, J. and Li, S.-M.: Organosulfate formation during the uptake of pinonaldehyde on acidic sulfate aerosols, Geophys. Res. Lett., 33, L13808, https://doi.org/10.1029/2006GL026079, 2006a.

Liggio, J. and Li, S.-M.: Reactive uptake of pinonaldehyde on acidic aerosols, J. Geophys. Res., 111, 1111-1138, https://doi.org/10.1029/2005JD006978, 2006b.

Lim, Y. B. and Ziemann, P. J.: Products and Mechanism of Secondary Organic Aerosol Formation from Reactions of n-Alkanes with $\mathrm{OH}$ Radicals in the Presence of $\mathrm{NO}_{x}$, Environ. Sci. Technol., 39, 9229-9236, https://doi.org/10.1021/es051447g, 2005.

Ludwig, J. and Klemm, O.: Acidity of size-fractionated aerosol particles, Water Air Soil Poll., 49, 35-50, https://doi.org/10.1007/BF00279508, 1990.

Madon, R. J. and Iglesia, E.: Catalytic reaction rates in thermodynamically non-ideal systems, J. Mol. Catal. A-Chem., 163, 189204, 2000.

McMurry, P. H. and Grosjean, D.: Gas and aerosol wall losses in Teflon film smog chambers, Environ. Sci. Technol., 19, 11761182, https://doi.org/10.1021/es00142a006, 1985.

Menut, L., Bessagnet, B., Khvorostyanov, D., Beekmann, M., Blond, N., Colette, A., Coll, I., Curci, G., Foret, G., Hodzic, A., Mailler, S., Meleux, F., Monge, J.-L., Pison, I., Siour, G., Turquety, S., Valari, M., Vautard, R., and Vivanco, M. G.: CHIMERE 2013: a model for regional atmospheric composition modelling, Geosci. Model Dev., 6, 981-1028, https://doi.org/10.5194/gmd-6-981-2013, 2013.

Müller, L., Reinnig, M.-C., Naumann, K. H., Saathoff, H., Mentel, T. F., Donahue, N. M., and Hoffmann, T.: Formation of 3methyl-1,2,3-butanetricarboxylic acid via gas phase oxidation of pinonic acid - a mass spectrometric study of SOA aging, Atmos. Chem. Phys., 12, 1483-1496, https://doi.org/10.5194/acp12-1483-2012, 2012.

Murphy, B. N. and Pandis, S. N.: Simulating the formation of semivolatile primary and secondary organic aerosol in a regional chemical transport model, Environ. Sci. Technol., 43, 47224728, https://doi.org/10.1021/es803168a, 2009.

Mutzel, A., Rodigast, M., Iinuma, Y., Böge, O., and Herrmann, H.: Monoterpene SOA - Contribution of firstgeneration oxidation products to formation and chemical composition, Atmos. Environ., 130, 136-144, https://doi.org/10.1016/j.atmosenv.2015.10.080, 2016.

Ng, N. L., Chhabra, P. S., Chan, A. W. H., Surratt, J. D., Kroll, J. H., Kwan, A. J., McCabe, D. C., Wennberg, P. O., Sorooshian, A., 
Murphy, S. M., Dalleska, N. F., Flagan, R. C., and Seinfeld, J. H.: Effect of $\mathrm{NO}_{x}$ level on secondary organic aerosol (SOA) formation from the photooxidation of terpenes, Atmos. Chem. Phys., 7, 5159-5174, https://doi.org/10.5194/acp-7-5159-2007, 2007a.

Ng, N. L., Kroll, J. H., Chan, A. W. H., Chhabra, P. S., Flagan, R. C., and Seinfeld, J. H.: Secondary organic aerosol formation from $m$-xylene, toluene, and benzene, Atmos. Chem. Phys., 7, 3909-3922, https://doi.org/10.5194/acp-7-3909-2007, 2007b.

Odum, J. R., Hoffmann, F., Bowman, D., Collins, D., Flagan, R. C., and Seinfeld, J. H.: Gas/particle partitioning and secondary organic aerosol yields, Environ. Sci. Technol., 30, 2580-2585, https://doi.org/10.1021/es950943+, 1996.

Pankow, J. F.: An absorption model of gas/particle partitioning of organic compounds in the atmosphere, Atmos. Environ., 28, 185-188, 1994.

Pun, B. K. and Seigneur, C.: Investigative modeling of new pathways for secondary organic aerosol formation, Atmos. Chem. Phys., 7, 2199-2216, https://doi.org/10.5194/acp-7-2199-2007, 2007.

Pun, B. K., Griffin, R. J., Seigneur, C., and Seinfeld, J. H.: Secondary organic aerosol. 2. Thermodynamic model for gas/particle partitioning of molecular constituents, J. Geophys. Res., 107, 4333, https://doi.org/10.1029/2001JD000542, 2002.

Pun, B. K., Seigneur, C., and Lohman, K.: Modeling secondary organic aerosol formation via multiphase partitioning with molecular data, Environ. Sci. Technol., 40, 4722-4731, https://doi.org/10.1021/es0522736, 2006.

Rahimpour, M. R.: A non-ideal rate-based model for industrial urea thermal hydrolyser, Chem. Eng. Process., 43, 1299-1307, https://doi.org/10.1016/j.cep.2003.12.005, 2004.

Robinson, A. L., Donahue, N. M., Shrivastava, M. K., Weitkamp, E. A., Sage, A. M., Grieshop, A. P., Lane, T. E., Pierce, J. R., and Pandis, S. N.: Rethinking Organic Aerosols: Semivolatile Emissions and Photochemical Aging, Science, 315, 1259-1262, https://doi.org/10.1126/science.1133061, 2007.

Roldin, P., Eriksson, A. C., Nordin, E. Z., Hermansson, E., Mogensen, D., Rusanen, A., Boy, M., Swietlicki, E., Svenningsson, B., Zelenyuk, A., and Pagels, J.: Modelling non-equilibrium secondary organic aerosol formation and evaporation with the aerosol dynamics, gas- and particle-phase chemistry kinetic multilayer model ADCHAM, Atmos. Chem. Phys., 14, 7953-7993, https://doi.org/10.5194/acp-14-7953-2014, 2014.

Santiago, M., Garcia Vivanco, M., and Stein, A.: $\mathrm{SO}_{2}$ effect on secondary organic aerosol from a mixture of anthropogenic VOCs: experimental and modelled results, Int. J. Environ. Pollut., 50, 224-233, 2012a.

Santiago, M., Vivanco, M. G., and Stein, A. F.: Evaluation of CMAQ parameterizations for SOA formation from the photooxidation of alpha-pinene and limonene against smog chamber data, Atmos. Environ., 56, 236-245, https://doi.org/10.1016/j.atmosenv.2012.04.011, 2012b.

Sato, K., Takami, A., Kato, Y., Seta, T., Fujitani, Y., Hikida, T., Shimono, A., and Imamura, T.: AMS and LC/MS analyses of SOA from the photooxidation of benzene and 1,3,5trimethylbenzene in the presence of NOx: effects of chemical structure on SOA aging, Atmos. Chem. Phys., 12, 4667-4682, https://doi.org/10.5194/acp-12-4667-2012, 2012.

Sato, K., Jia, T., Tanabe, K., Morino, Y., Yoshizumi Kajii, Y., and Imamura, T.: Terpenylic acid and nine-carbon multifunc- tional compounds formed during the aging of $\beta$-pinene ozonolysis secondary organic aerosol, Atmos. Environ., 130, 127-135, https://doi.org/10.1016/j.atmosenv.2015.08.047, 2016.

Saunders, S. M., Jenkin, M. E., Derwent, R. G., and Pilling, M. J.: Protocol for the development of the Master Chemical Mechanism, MCM v3 (Part A): tropospheric degradation of nonaromatic volatile organic compounds, Atmos. Chem. Phys., 3, 161-180, https://doi.org/10.5194/acp-3-161-2003, 2003.

Schell, B., Ackermann, I. J., Hass, H., Binkowski, F. S., and Ebel, A.: Modeling the formation of secondary organic aerosol within a comprehensive air quality model system, J. Geophys. Res., 106, 28275-28293, https://doi.org/10.1029/2001JD000384, 2001.

Schilling, K. A.: Secondary Organic Aerosol Composition Studies Using Mass Spectrometry, $\mathrm{PhD}$ thesis, California Institute of Technology, https://doi.org/10.7907/Z93F4MJR, 2015.

Seinfeld, J. and Pandis, S.: Atmospheric chemistry and physics: from air pollution to climate change, A Wiley interscience publication, Wiley, 1998.

Shrivastava, M., Fast, J., Easter, R., Gustafson Jr., W. I., Zaveri, R. A., Jimenez, J. L., Saide, P., and Hodzic, A.: Modeling organic aerosols in a megacity: comparison of simple and complex representations of the volatility basis set approach, Atmos. Chem. Phys., 11, 6639-6662, https://doi.org/10.5194/acp11-6639-2011, 2011.

Shrivastava, M. K., Lane, T. E., Donahue, N. M., Pandis, S. N., and Robinson, A. L.: Effects of gas particle partitioning and aging of primary emissions on urban and regional organic aerosol concentrations, J. Geophys. Res., 113, D18301, https://doi.org/10.1029/2007JD009735, 2008.

Song, M., Liu, P. F., Hanna, S. J., Zaveri, R. A., Potter, K., You, Y., Martin, S. T., and Bertram, A. K.: Relative humiditydependent viscosity of secondary organic material from toluene photo-oxidation and possible implications for organic particulate matter over megacities, Atmos. Chem. Phys., 16, 8817-8830, https://doi.org/10.5194/acp-16-8817-2016, 2016.

Surratt, J. D., Murphy, S. M., Kroll, J. H., Ng, N. L., Hildebrandt, L., Sorooshian, A., Szmigielski, R., Vermeylen, R., Maenhaut, W., Claeys, M., Flagan, R. C., and Seinfeld, J. H.: Chemical composition of secondary organic aerosol formed from the photooxidation of isoprene, J. Phys. Chem. A, 110, 9665-9690, https://doi.org/10.1021/jp061734m, 2006.

Svendby, T. M., Lazaridis, M., and Tørseth, K.: Temperature dependent secondary organic aerosol formation from terpenes and aromatics, J. Atmos. Chem., 59, 25-46, https://doi.org/10.1007/s10874-007-9093-7, 2008.

Trump, E. R. and Donahue, N. M.: Oligomer formation within secondary organic aerosols: equilibrium and dynamic considerations, Atmos. Chem. Phys., 14, 3691-3701, https://doi.org/10.5194/acp-14-3691-2014, 2014.

Tulet, P., Grini, A., Griffin, R. J., and Petitcol, S.: ORILAM-SOA: A computationally efficient model for predicting secondary organic aerosols in three-dimensional atmospheric models, J. Geophys. Res., 111, D23208, https://doi.org/10.1029/2006JD007152, 2006.

Verwer, J. G., Spee, E. J., Bloom, J. G., and Hundsdorfer, W.: A second-order rosenbrock method applied to photochemical dispersion problems, SIAM J. Sci. Comput., 20, 1456-1480, https://doi.org/10.1137/S1064827597326651, 1999. 
Vivanco, M. G., Santiago, M., Martínez-Tarifa, A., Borrás, E., Ródenas, M., García-Diego, C., and Sánchez, M.: SOA formation in a photoreactor from a mixture of organic gases and HONO for different experimental conditions, Atmos. Environ., 45, 708715, https://doi.org/10.1016/j.atmosenv.2010.09.059, 2011.

Vivanco, M. G., Santiago, M., Sánchez, M., Clavero, M. A., Borrás, E., Ródenas, M., Alacreu, F., Vásquez, M., Clemente, E., Porras, R., Muñoz, A., and Stein, A.: Experimental data on SOA formation from mixtures of anthropogenic and biogenic organic compounds, Atmósfera, 26, 59-73, 2013.

Vivanco, M. G., Couvidat, F., Seigneur, C., Jang, M., Santiago, M., and Bessagnet, B.: Evaluation of some SOA formation schemes for the oxidation of anthropogenic gases against experiments in two outdoor chambers, Int. J. Environ. Pollut., 59, 43-55, https://doi.org/10.1504/IJEP.2016.078062, 2016.

Volkamer, R., Platt, U., and Wirtz, K.: Primary and secondary glyoxal formation from aromatics: experimental evidence for the bicycloalkyl-radical pathway from benzene, toluene, and p-xylene, J. Phys. Chem. A, 105, 7865-7874, https://doi.org/10.1021/jp010152w, 2001.

WHO: Health Aspects of Air Pollution with Particulate Matter, Ozone and Nitrogen Dioxide, WHO Working Group, Bonn, Germany, Tech. rep., WHO EUR/03/5042688, 2003.

Yu, S., Bhave, P. V., Dennis, R. L., and Marthur, R.: Seasonal and regional variations of primary and secondary organic aerosols over the Continental United States: Semi-empirical estimates and model evaluation, Environ. Sci. Technol., 41, 4690-4697, https://doi.org/10.1021/es061535g, 2007.

Zhang, Q., Jimenez, J. L., Canagaratna, M. R., Allan, J. D., Coe, H., Ulbrich, I., Alfarra, M. R., Takami, A., Middlebrook, A. M., Sun, Y. L., Dzepina, K., Dunlea, E., Docherty, K., DeCarlo, P. F., Salcedo, D., Onasch, T., Jayne, J. T., Miyoshi, T., Shimono, A., Hatakeyama, S., Takegawa, N., Kondo, Y., Schneider, J., Drewnick, F., Borrmann, S., Weimer, S., Demerjian, K., Williams, P., Bower, K., Bahreini, R., Cottrell, L., Griffin, R. J., Rautiainen, J., Sun, J. Y., Zhang, Y. M., and Worsnop, D. R.: Ubiquity and dominance of oxygenated species in organic aerosols in anthropogenically-influence Northern Hemisphere mildlatitudes, Geophys. Res. Lett., 34, L13801, https://doi.org/10.1029/2007GL029979, 2007.
Zhang, X., Cappa, C. D., Jathar, S. H., Mcvay, R. C., Ensberg, J. J., Kleeman, M. J., and Seinfeld, J. H.: Influence of vapor wall loss in laboratory chambers on yields of secondary organic aerosol, P. Natl. Acad. Sci. USA, 111, 5802-5807, https://doi.org/10.1073/pnas.1404727111, 2014.

Zhang, X., Schwantes, R. H., McVay, R. C., Lignell, H., Coggon, M. M., Flagan, R. C., and Seinfeld, J. H.: Vapor wall deposition in Teflon chambers, Atmos. Chem. Phys., 15, 4197-4214, https://doi.org/10.5194/acp-15-4197-2015, 2015.

Zuend, A. and Seinfeld, J. H.: Modeling the gas-particle partitioning of secondary organic aerosol: the importance of liquidliquid phase separation, Atmos. Chem. Phys., 12, 3857-3882, https://doi.org/10.5194/acp-12-3857-2012, 2012.

Zuend, A., Marcolli, C., Luo, B. P., and Peter, T.: A thermodynamic model of mixed organic-inorganic aerosols to predict activity coefficients, Atmos. Chem. Phys., 8, 4559-4593, https://doi.org/10.5194/acp-8-4559-2008, 2008.

Zuend, A., Marcolli, C., Booth, A. M., Lienhard, D. M., Soonsin, V., Krieger, U. K., Topping, D. O., McFiggans, G., Peter, T., and Seinfeld, J. H.: New and extended parameterization of the thermodynamic model AIOMFAC: calculation of activity coefficients for organic-inorganic mixtures containing carboxyl, hydroxyl, carbonyl, ether, ester, alkenyl, alkyl, and aromatic functional groups, Atmos. Chem. Phys., 11, 9155-9206, https://doi.org/10.5194/acp-11-9155-2011, 2011. 